\title{
FEASIBILITY STUDY ON WIND ENERGY HARVESTING SYSTEM IMPLEMENTATION IN MOVING TRAINS
}

\author{
Venera Nurmanova, B.Eng.
}

Submitted in fulfillment of the requirements

for the degree of Masters of Science

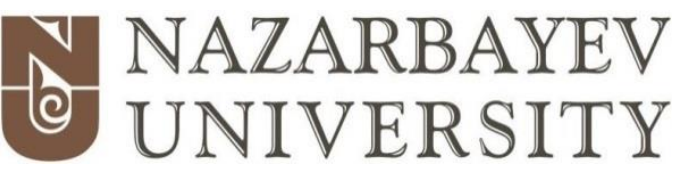

\author{
School of Engineering \\ Department of Electrical \& Electronic Engineering \\ Nazarbayev University
}

53 Kabanbay Batyr Avenue,

Astana, Kazakhstan, 010000

December, 2016 


\section{Abstract}

Feasibility study on implementing wind power generation on moving train is discussed in this Thesis. Wind turbines installation over the train roof is suggested and tested from different aspects. Practical aspects of wind energy utilization are discussed and challenges are highlighted. Calculations of wind power generation for wagon roof mounted turbine are provided and air drag of turbine is discussed. Simulation study is performed in SolidWorks environment to explore air drag influence of wind turbines on moving train. Simulation of wind power generation is also conducted in MATLAB Simulink. Analytically the generated power is compared to mechanical power required to overcome the extra air drag caused by wind turbines over the train wagons.

Economical profit of the suggested design is also discussed in detail. The fuel economy and resultant decrease of the carbon dioxide emission have shown the reasonableness of investments on wind turbine implementation on the passenger trains. The payback period calculations for different scenarios are also discussed at the end. 


\section{Acknowledgements}

I would like to express my sincere gratitude to my Supervisor Professor Mehdi Bagheri for his support and guidance throughout the completion of the thesis. His unquenchable energy has been both inspiration and motivation for me, and constructive comments and feedbacks given during meetings helped to keep the right track in pursuing the quality work.

I also want to thank my family and friends who supported me during this journey and never lost the faith in me. 


\section{Publications}

1) V. Nurmanova, M. Bagheri, "Feasibility Study on Wind Energy Harvesting System Implementation in Moving Trains", IET Science, Measurement \& Technology, Submitted, Jan 2017.

2) V. Nurmanova, M. Bagheri, "Wind Energy Harvesting System Implementation in Moving Trains: A Feasibility Study", IEEE International Siberian Conference on Control and Communications (SIBCON-2017), submitted, 2017. 


\section{Table of Contents}

Abstract ..........................................................................................................................

Acknowledgements ............................................................................................................ii

Publications...................................................................................................

List of Abbreviations........................................................................................... vi

List of Figures ............................................................................................................ vii

List of Tables.................................................................................................. viii

Chapter 1 - Introduction..............................................................................................1

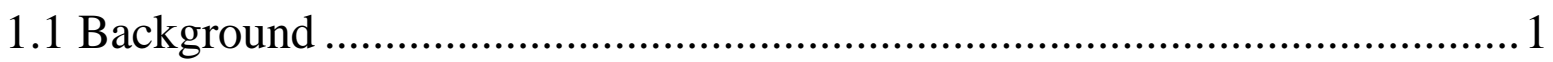

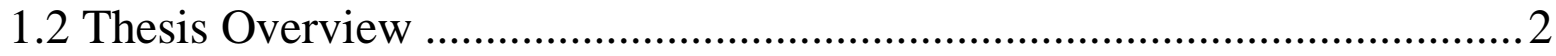

1.3 Outline

Chapter 2 - Literature Review .......................................................................................4

Chapter 3 - Modelling and Analytical Calculations............................................14

3.1 System Overview …………………………………………………....... 14

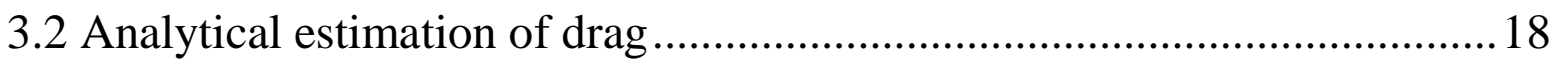

Chapter 4 - Simulations .......................................................................................................24

4.1 Simulation parameters.............................................................................24

4.2 MATLAB and SolidWorks simulations ………………………………....28

Chapter 5 - Results and Discussions .........................................................................32

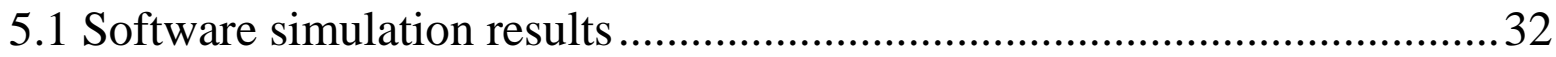

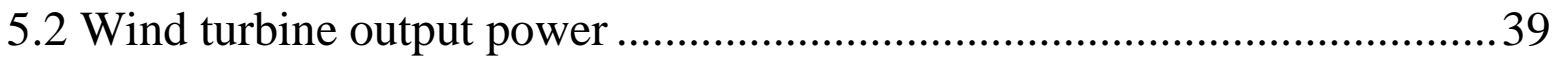

Chapter 6 - Conclusions and Future Work................................................................46 


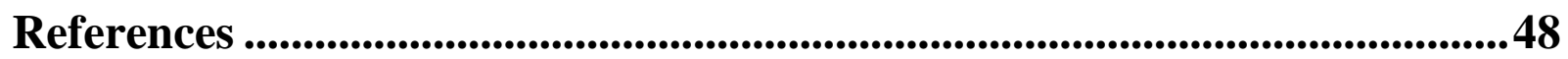

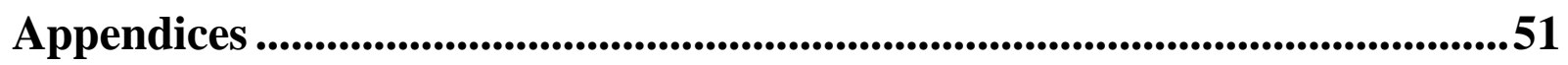

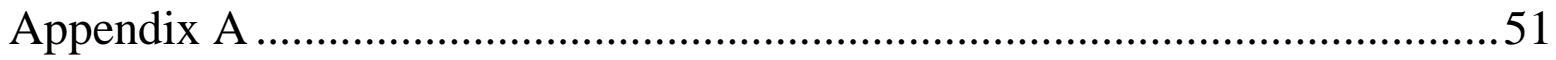

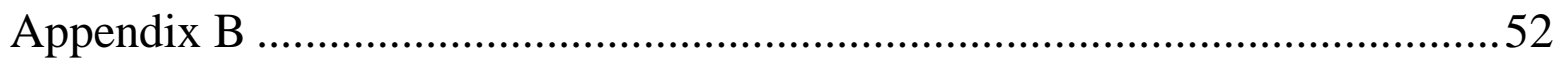

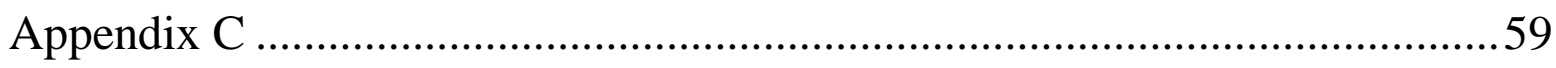




\section{List of Abbreviations}

$\begin{array}{ll}\text { AC } & \text { Alternating current } \\ \text { DC } & \text { Direct current } \\ \text { HAWT } & \text { Horizontal axis wind turbine } \\ \text { IG } & \text { Induction generator } \\ \text { PMSG } & \text { Permanent magnet synchronous generator } \\ \text { VAWT } & \text { Vertical axis wind turbine }\end{array}$




\section{List of Figures}

Figure 2. 1: Alternative fuel stations by type ................................................. 4

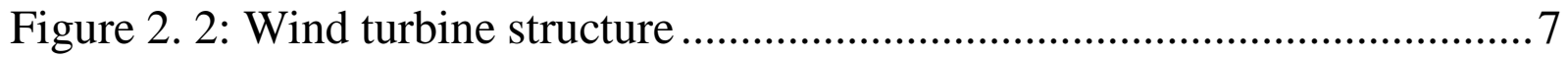

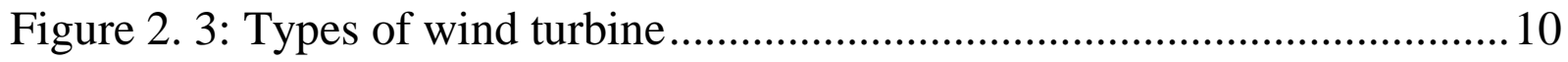

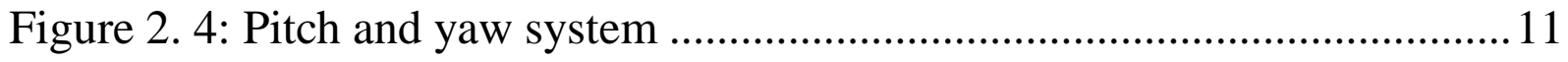

Figure 2.5: Ducting system for HAWT and VAWT .......................................... 12

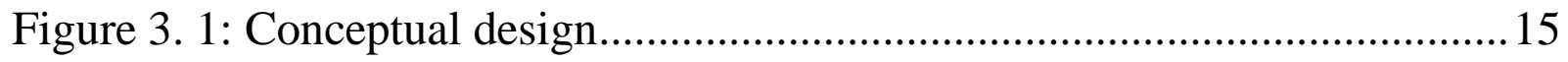

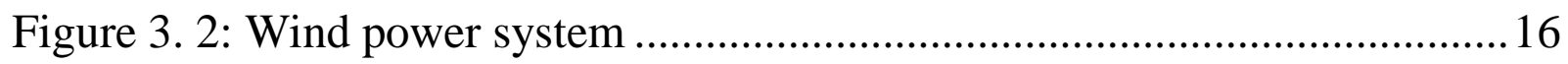

Figure 3. 3: Drag coefficient for different vanes angle in frame vs. wind speed 19

Figure 3. 4: Train frontal area estimation ....................................................... 19

Figure 4. 1: Route (fast) Astana-Almaty on the map of Kazakhstan...................25

Figure 4. 2: Route (slow) Astana-Almaty on the map of Kazakhstan .................25

Figure 4. 3: MATLAB Simulink model...........................................................29

Figure 4. 4: SolidWorks flow simulation for simple wagon................................30

Figure 4. 5: SolidWorks flow simulation for wagon with turbines ......................30

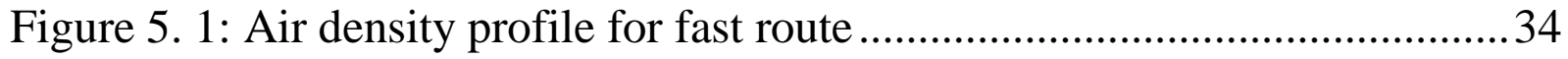

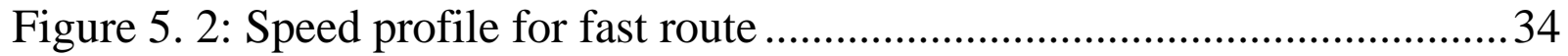

Figure 5. 3: Output power profile for fast route................................................... 35

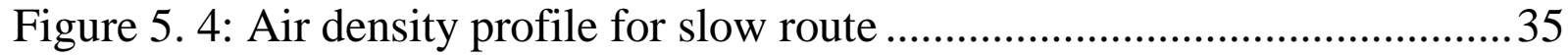

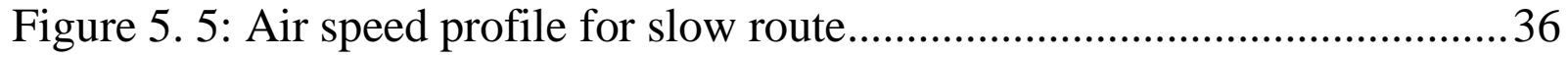

Figure 5. 6: Output power profile for slow route ................................................. 36

Figure 5. 7: Air speed profiles comparison for fast route .................................... 37

Figure 5. 8: Air speed profilse comparison for slow route .................................. 37

Figure 5. 9: Comparison of financial gain for fast route.....................................43

Figure 5. 10: Comparison of financial gain for slow route ..................................43

Figure 5. 11: Payback period for fast route....................................................... 44

Figure 5. 12: Payback period for slow route …….............................................. 45 


\section{List of Tables}

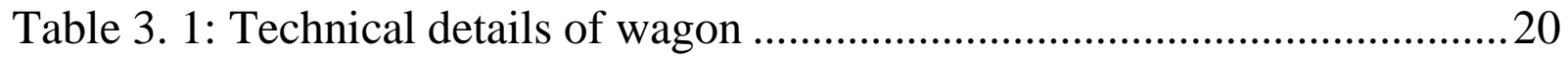

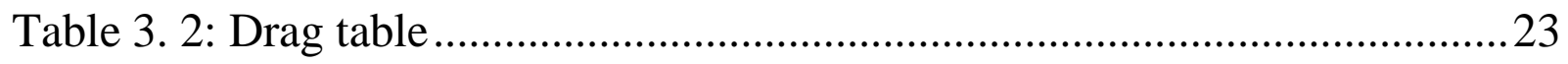

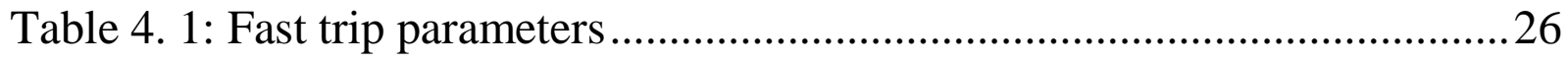

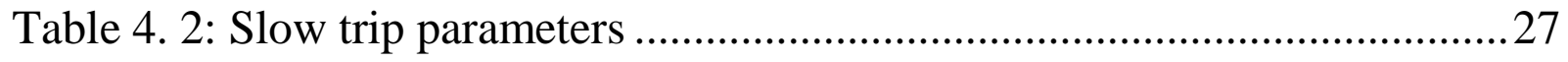

Table 5. 1: SolidWorks data for flow simulation.................................................. 38

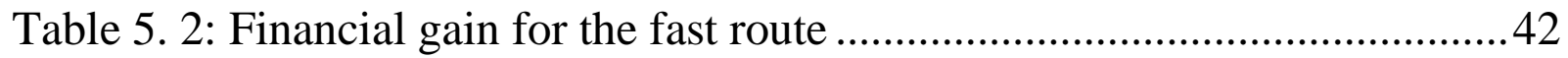

Table 5. 3: Financial gain for the slow route ......................................................42 


\section{Chapter 1 - Introduction}

\subsection{Background}

Global warming challenge along with fossil fuels depletion caused that governments as well as researchers pay serious attention to the renewable and green energy resources in recent years. Therefore the proportion of vehicles driving on renewable sources of energy is rapidly increasing. In addition, implementation of alternatives gives an actual opportunity to consumers to become independent from fossil fuel resources and market issues.

Despite the fact that electric and hybrid cars are becoming routine transportation vehicles, implementation of green energy in larger vehicles (buses, planes) is still innovative. Nevertheless, different researches are being conducted regarding the utilization of wind and solar energy on trucks, buses and trains [1].

It is a common practice to manufacture vehicles which utilize alternative sources of energy such as biogas, ethanol, compressed and liquefied natural gas instead of conventional fossil fuel. However usage of wind or solar energy is considerably innovative technique and requires feasibility study on various prospective such as mechanical design and power output capabilities. 


\subsection{Thesis Overview}

The following Thesis will be focused on wind energy power generation on moving trains. Since the speed of the air flow facing the wind turbine blades will be equal to speed of the train, hence kinetic energy of that air might be utilized for electricity generation [2].

The simulation of the wagon with wind power system unit installed on its roof will be conducted in this Thesis. The unit includes horizontally aligned vertical wind turbine, gearbox and generator, along with battery storage unit which will be installed inside the wagon. Air flow simulations will be conducted in order to define the optimum location for the wind power generation unit, so to minimize the undesired air reluctance. The economic and ecological profit of implementing wind turbines on roof of train will be discussed. The power generation capabilities of the wind turbine will be assessed for further estimation of feasibility of proposed model.

\subsection{Outline}

The Thesis is organized as follows. Chapter 2 presents the literature review relevant for subsequent work. The methodology is discussed in Chapter 3, considering input parameters and analytical estimation of the air drag. Chapter 4 will convey the information regarding the simulation of the electrical and 
mechanical design of the system. The simulation results will be discussed in Chapter 5, including power savings, additional drag force, and financial profit. Conclusion will be drawn in Chapter 6 along with the discussion of the future work. 


\section{Chapter 2 - Literature Review}

The amount of fueling stations in the United States of America according to the type of alternative sources of energy for cars is illustrated in Figure 2.1. It is observed that at the end of $20^{\text {th }}$ century almost all types of vehicles used propane and compressed natural gas instead of conventional gasoline and diesel. Afterwards, due to technology development more vehicles have been used biofuel, ethanol fuel blend and electricity. It should be noted, that the proportion of electricity driven vehicles increased significantly over the past 5 years [1].

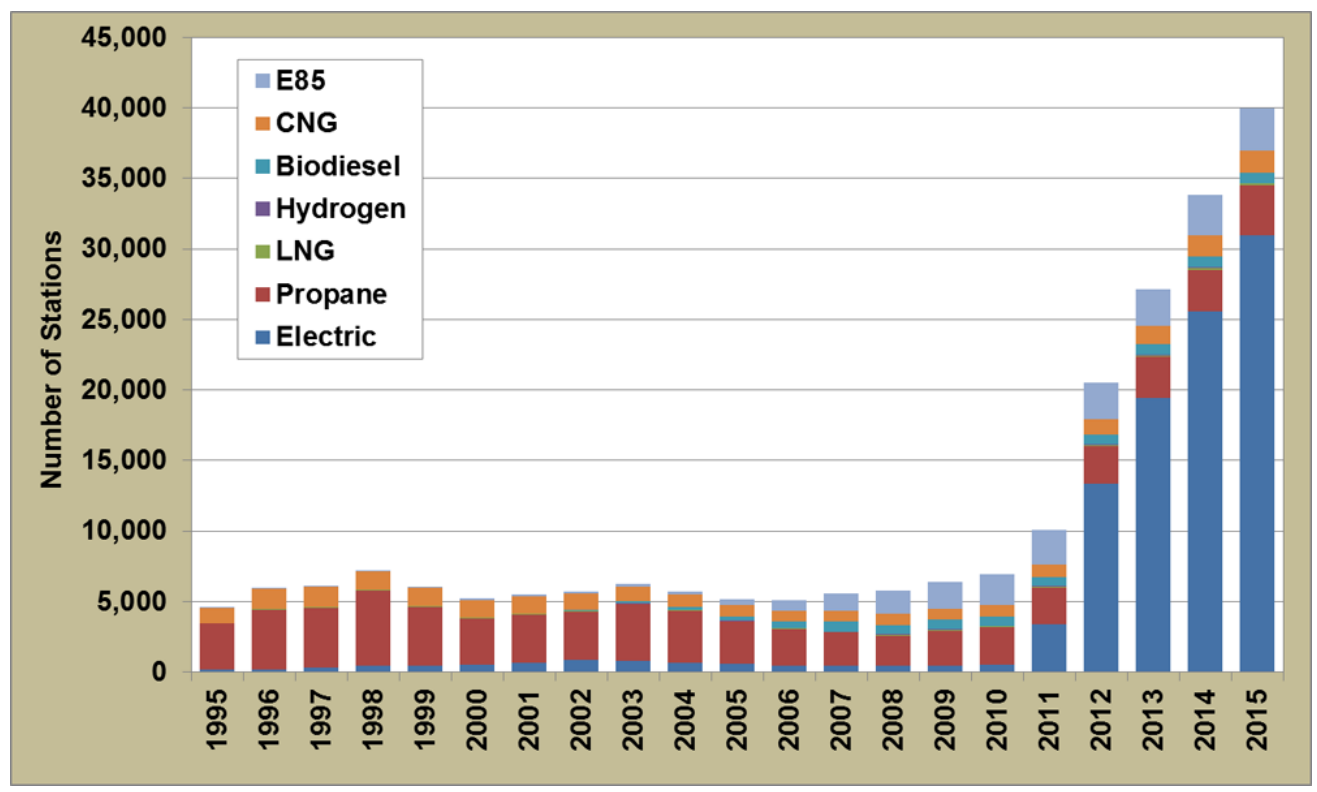

Figure 2. 1: Alternative fuel stations by type, taken and modified from [1]

Although automobile utilizing of renewable sources such as solar energy or biofuel in car have become a widespread practice, there are several successful 
projects introducing solar energy into other fields of transportation such as aviation and railways. In fact, to produce the amount of energy equivalent to what is generated by conventional sources the renewable and green sources require significantly larger power plant area. Total land required for different types of energy generation with similar output is as follows:

- $\quad$ Nuclear power station - 1.8 GW, 1.7 miles $^{2}$;

- Wind turbines required to generate $-1.8 \mathrm{GW}, 169$ miles $^{2}$;

- $\quad$ Solar plant - 1.8 GW, 21 miles $^{2}[3]$.

In this context, implementation of renewable energy on moving train is quite innovative approach. Considering the total fuel consumption of the train, the power generated by available renewable resources seems to be insufficient. Therefore, numerous researches are being conducted in order to investigate possible scenario to reach maximum utilization of alternative energy on the train. According to [4]-[6], renewable sources such as wind, solar and biomass (human waste) are considered to be the most efficient supplementary resources for generating power in the train. Particularly, it is supposed to use the roof of the train wagon for installation of solar panels or wind turbines. However, there are some challenges such as additional air drag created by mounted turbine over the train roof. As the other alternative the human waste can undergo digestion 
process and further is used as a biofuel [7]-[9]. The development of alternative energy generation for rail transportation system has been widely discussed and started in India, Denmark and Netherlands, where roof of trains are already covered by solar panels, and couple of states has connected wind turbine generators to electric train overhead lines [5], [8], [10].

Prior to reach the detailed discussion on mechanical and electrical aspects of the project, technical background of the wind turbines and calculation of power generated is discussed. Figure 2.2 shows the foundation and tower as the major parts of the wind turbine. The highest wind turbines have the tower made from concrete and steel structure in order to increase its strength, as all the supplementary components such as gearbox and generator are installed at the top of the tower in a nacelle. Shorter wind turbines of about 20 meters usually have all the electrical components installed on the ground near foundation. Majority of commercial wind turbines have 3 blades, however in rural areas or small scale installations number of the blades might be increased. 


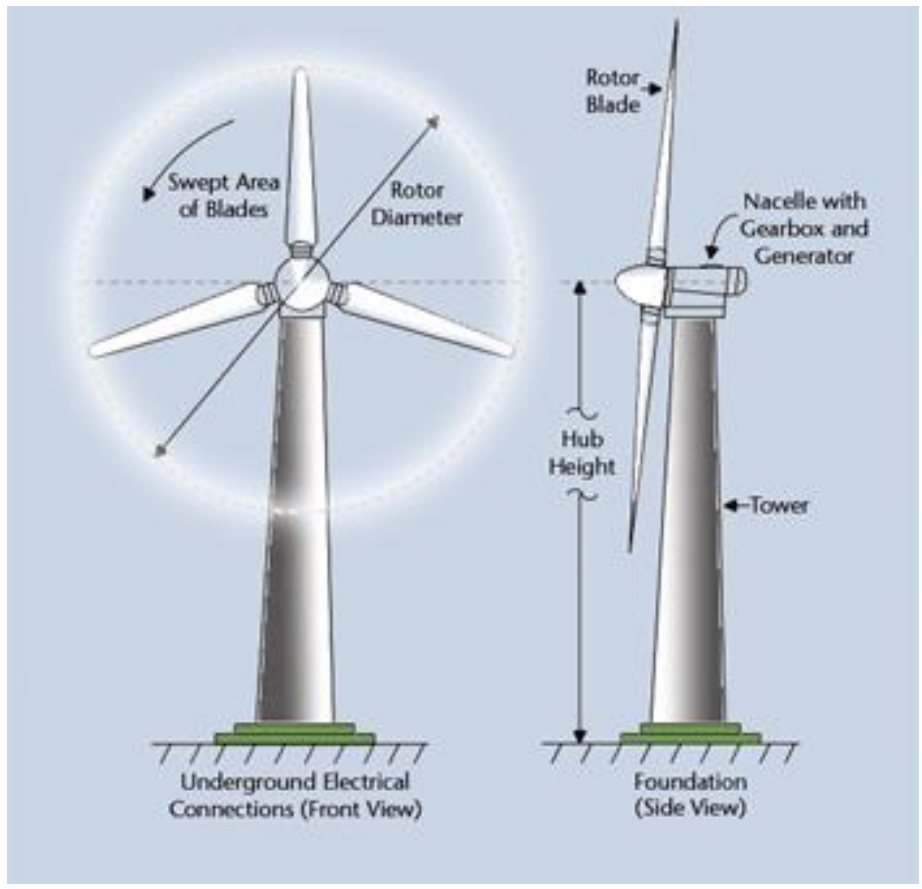

Figure 2. 2: Wind turbine structure, taken and modified from [5]

The equation of energy generated by wind turbine is common for all tower designs and is expressed in (1.1) and is derived using Newton's second law and momentum theory [4]:

$$
W_{\text {total }}=\frac{1}{2} \rho A V^{3} C_{P}
$$

where $\rho$ is the density of air in $\mathrm{kg} / \mathrm{m}^{3}, A$ is area swept by blades in $\mathrm{m}^{2}, V$ is the wind speed in $\mathrm{m} / \mathrm{s}$ and $C_{P}$ is the power coefficient, which value can reach maximum 0.59 (also known as Betz limit) for ideal turbine [5], [11].

In addition, there are parameters, which overcome alternations due to change of geographic position. For example, the change in altitude and ambient 
temperature has an impact on the air density [6]. The relation can be expressed as,

$$
\rho=\frac{P}{R T}
$$

Where $P$ is the atmospheric pressure in $k P a, T$ is the ambient temperature in $K$, and $R$ is a gas constant and is equal to $0.29 \mathrm{kPa} \cdot \mathrm{m}^{3} / \mathrm{kg} \cdot \mathrm{K}$ for air.

It was discussed before that the kinetic energy of the wind is converted into mechanical energy of the blades, which in turn rotate shaft of the turbine. At this stage it is crucial to understand that the rotation of the turbine shaft is not enough to generate electricity in proper level, in other word the number of rotations per minute should be increased to reach optimum turning point of generator and produce energy [12], [14], [15]. Therefore, gear system or in this case called gearbox is implemented in order to increase the angular velocity of the generator rotor shaft and reduce the torque by using conservation of momentum principle [7], [16].

There are several factors need to be taken into account while designing the overall system. For example, the instability of wind speed, change of air density according to the altitude, size and weight of the additional structure and created supplementary air reluctance are considered as some of those factors. 
These issues contribute to make the entire task more complex and raise the question of project feasibility both in practical and economical point of views.

In order to minimize this negative effect from air reluctance, the mechanical design of the structure should be modified. First of all, the wind turbine itself is the primary step to start the design of the wind power generation unit. In order to eliminate any confusion, it is important to primarily clarify the difference between wind turbine and the windmill: the first one converts mechanical energy into electrical, whereas in a windmill the mechanical energy is directly used by machinery [18], [19]. There are two major types of wind turbine:

- Horizontal Axis Wind Turbine (HAWT) - the axis of the blades rotation is horizontal to the ground, beneficial at high altitudes, it is one of the most widely used and commercialized types;

- Vertical Axis Wind Turbine (VAWT) - the axis of the blades rotation is vertical, used at lower altitudes (see Figure 2.3, taken and modified from [18]). 


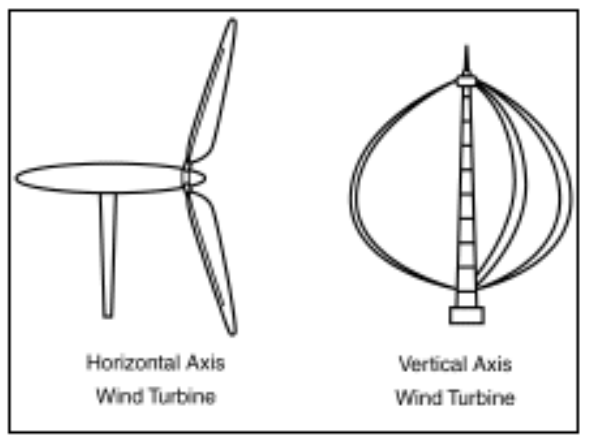

Figure 2. 3: Types of wind turbine

It is suggested to use VAWT for this study due to following reasons:

- $\quad$ beneficial at high wind speed typical for moving train;

- $\quad$ robust structure as HAWT will produce significantly more air drag;

- HAWT's blades are more likely to undergo mechanical damage due to high thrust;

- blades of the HAWT must be adjusted to wind direction by using pitch system, which is not required for VAWT;

- $\quad$ the starting torque for VAWT is higher compared to HAWT;

- in case of VAWT, additional components such as gearbox and generator are combined into more compact structure [8], [20].

It was previously mentioned that the concept of wind energy is to convert the kinetic energy of the air into mechanical energy (wind turbine), and then mechanical energy is converted into electrical energy (generator). Basically, 
electricity generated by renewable sources of energy such as wind and solar is usually stored in batteries, due to the fact that wind speed and solar radiation varies throughout the operation cycle. Nevertheless, the problem of fluctuations of generated power can be avoided by enhancing the design. For instance, it is a well-developed practice to implement parabolic solar cells in order to concentrate solar energy or even introduce sun-tracking capabilities through system of sensors and motors [3]-[6], [21]-[23]. Wind turbines can also be improved by modifying the conventional design, such as pitch and yaw systems to adjust the blades of the turbine according to direction of the wind and enhance the aerodynamic properties of the structure (see Figure 2.4).

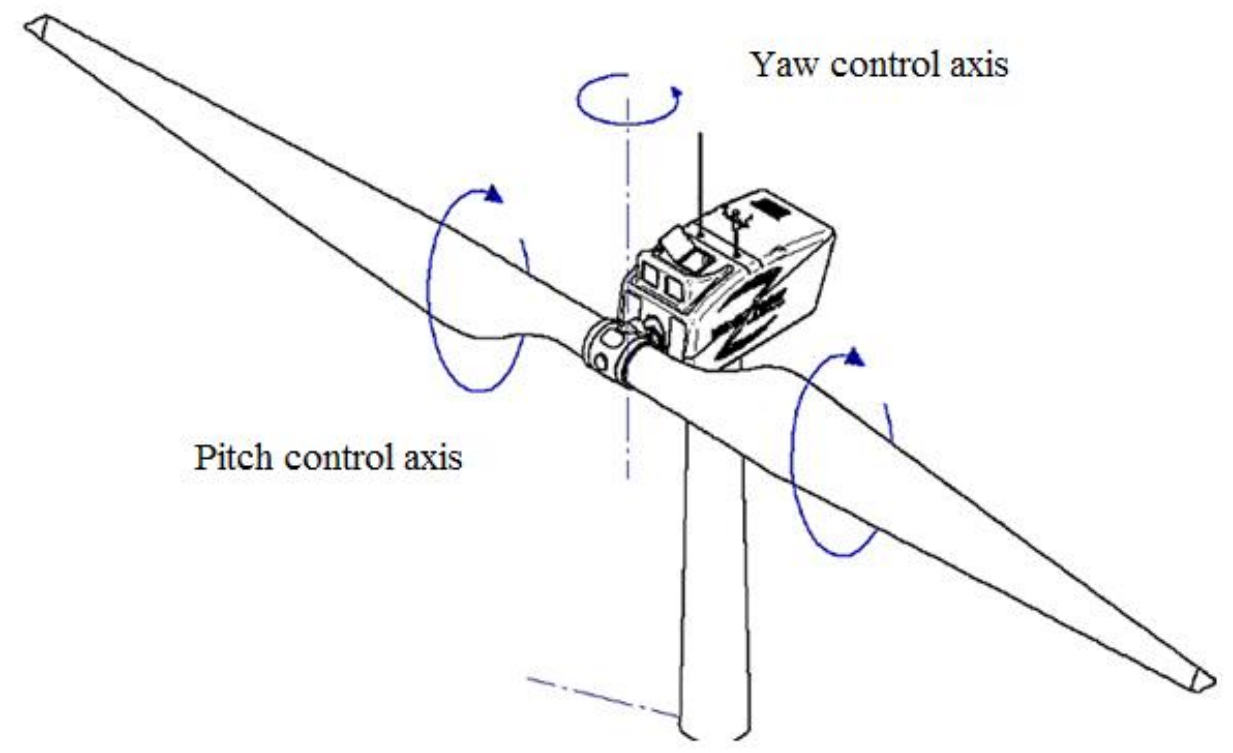

Figure 2. 4: Pitch and yaw system, taken and modified from [4] 
As it is obvious in Figure 2.4 the pitch and yaw control systems are beneficial in case of HAWT, whereas VAWT does not require systematic adjustment blades angle. Sufficiently high wind speed is enough for VAWT, this can be guaranteed by implementation of duct, which will concentrate and guide the air flow directly to the blade of the turbine. The additional component ducted around the turbine is also called augmenter, and it basically amplifies the wind speed and directs the air flow towards blades. Similar technique has been used for HAWT, since it allows avoiding the relatively expensive angle adjustment system. Figure 2.5 represents the conceptual design of this mentioned approach.
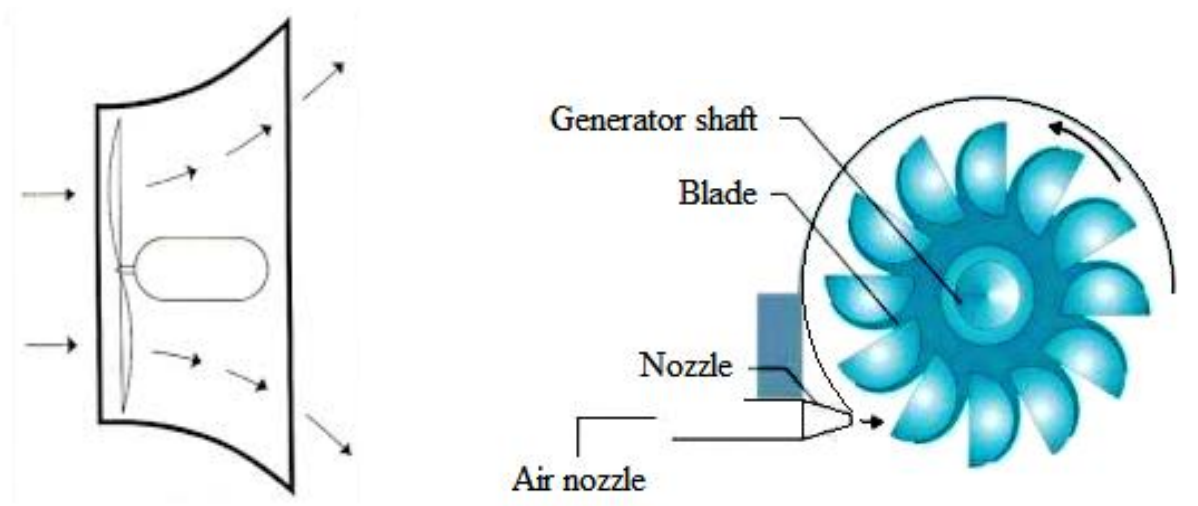

Figure 2. 5: Ducting system for HAWT and VAWT, taken and modified from [9]

Recent studies and empirical data show an augmenter or simple duct will significantly improve the efficiency and net power generated by wind turbine. According to study of a group of researchers from Croatian University in Rijeka [10], this kind of modification increases the energy output by the factor of 
approximately 3-3.5. On the other hand, duct will create a shelter from precipitation and other mechanical damage, thus decreasing the necessity for frequent repairing works. 


\section{Chapter 3 - Modelling and Analytical}

\section{Calculations}

\subsection{System Overview}

The detailed description of the proposed model and necessary mathematical analysis will be discussed in this Chapter.

Mechanical and electrical features of the model were designed in order to optimize the existing engineering decisions and maximize the efficiency of the wind power generation system. It was previously discussed that the wind energy will be applied as a supplementary source for the train's conventional diesel power. It is known that during the train movement the air vacuum will be produced at the sides and the back of the wagon. Therefore an air with the speed equal to moving vehicle's velocity will rush there in order to fill that vacuum. Basically, the kinetic energy of that air might be used for generation of electricity. In other words, the energy of the wind will be transformed into mechanical energy of the blades of the wind turbine and further by connecting the rotor of the turbine to generator shaft, transferred into electrical energy according to principle of electromagnetic induction. 
The roof top of the train was chosen for installation point due to higher wind speed and less obstacles. Moreover, the area of the top is sufficient to locate all components of the system, including wind turbines, gearboxes, and generators, and consequently decreasing the necessity of long wiring. It is proposed to install five rows of pair of wind power systems on the train, each having height of $30 \mathrm{~cm}$ and length of one meter. As the length of the wagon is approximately 26.7 meters, the distance between every unit is sufficient enough to maintain the preferred air speed level at each unit (see Figure 3.1).

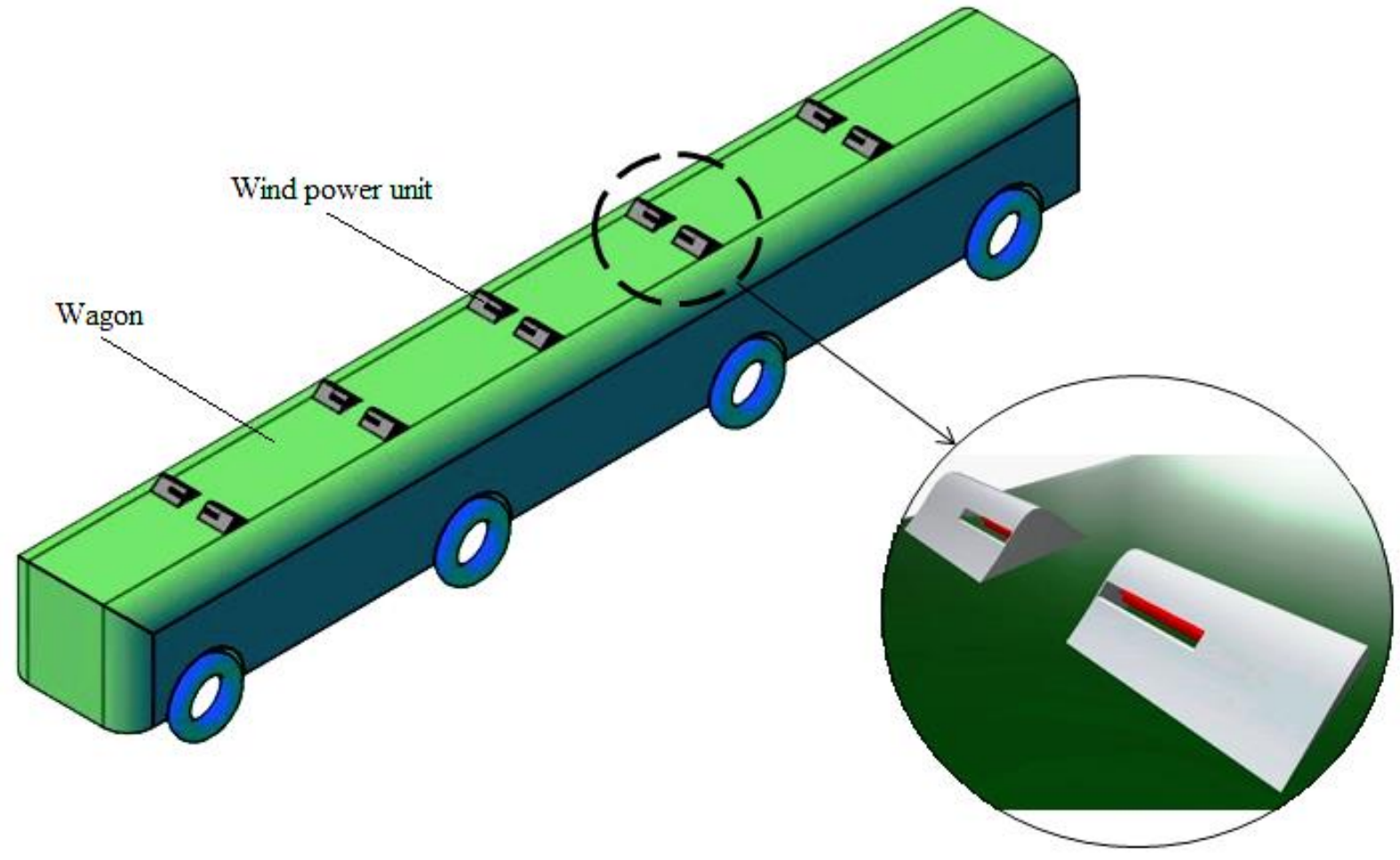

Figure 3. 1: Conceptual design 
Close-up sectional view of mounted unit containing wind turbine, gearbox and generator is illustrated in Figure 3.2. The form of the shelter mentioned in previous chapter is bell shaped streamlined body, in order to decrease the air drag exerted on the structure. The aluminum shelter has horizontal gaps from both sides, equal to the length of the wind turbine. These gaps function as a duct, which guarantees the preferable air flow pattern and speed regardless of the direction of the wind speed.

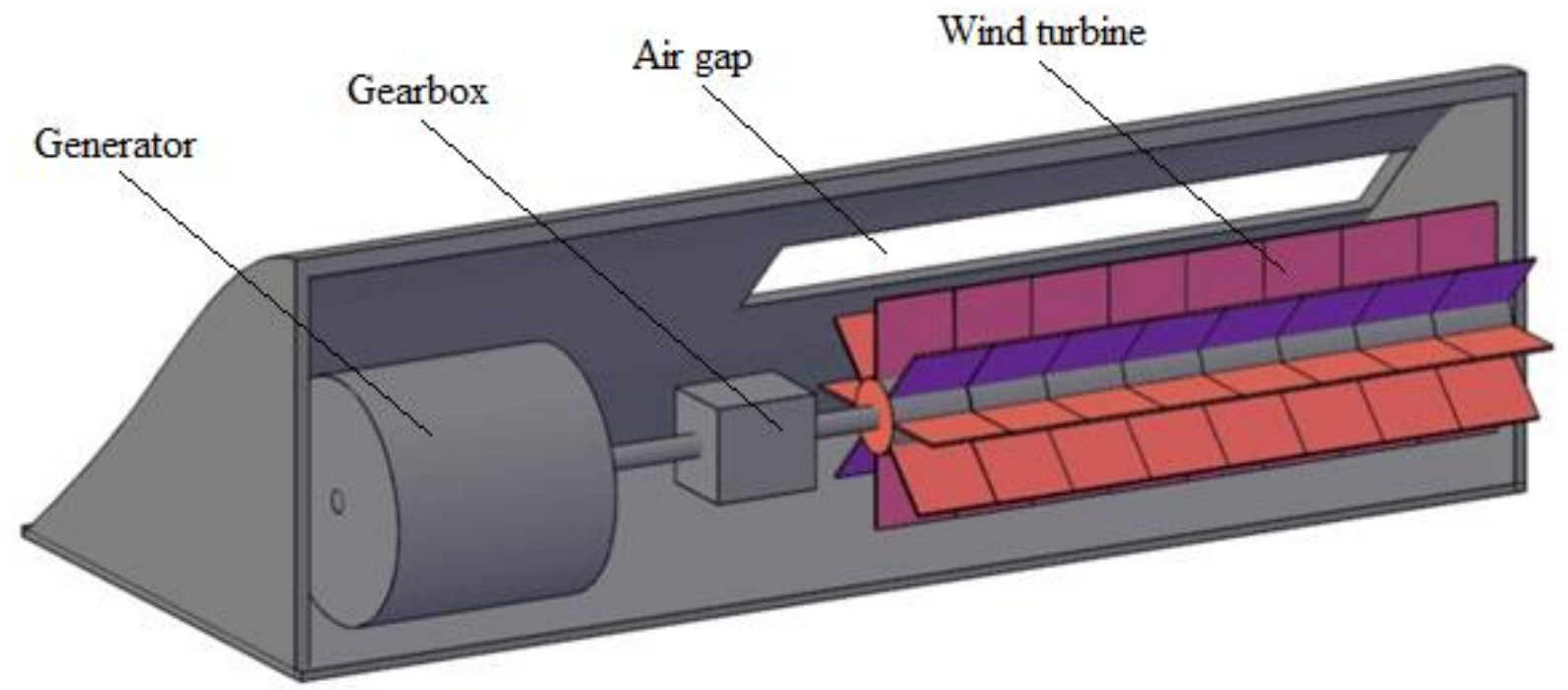

Figure 3. 2: Wind power system

The system components are conventional and include wind turbine, gearbox (redactor), and the power generator. Since the battery unit is located inside the wagon, it is not illustrated in Figure 3.2. It should be noted that the type of the wind turbine is horizontally aligned VAWT with six flat blades, 
which enables exploitation of extremely high wind speed available at the wagon roof. The chosen wind turbine type also satisfies area restrictions, since conventional wind turbines will require larger separation distance. The duct gaps are advised to situate on the inner side of the shelter, as the wind speed and direction there tends to be more desirable, rather than at the outer side. The visualization of this postulate will be provided in Chapter 4 .

Unlike traditional three bladed horizontal wind turbines, VAWT rotates at significantly higher angular speed. Nevertheless, it is suggested to use gearbox to regulate the shaft rotational speed and ensure the desired operating speed of generator rotor. The most commercialized types of generator are induction generator (IG) and permanent magnet synchronous generator (PMSG). Both generators operate at fixed rotational speed while being connected to the grid. In spite of economic feasibility of IG, it is strongly recommended to use more efficient PMSG, which in turn does not require additional capacitor for power factor correction [4], [5]. Nevertheless, due to existence of brushes in PMSG, which requires high maintenance and frequent repairing works, it is suggested to use AC PMSG with electronic rectification. The generator diameter is limited by $25 \mathrm{~cm}$, and generator-gearbox pair should not exceed $40 \mathrm{~cm}$ in total. 


\subsection{Analytical estimation of drag}

In Chapter 2, it was stated that the installation of the additional structure on the top of the train will increase the air drag exerted, which in turn will increase the power required in locomotive to overcome that extra drag force. Therefore, it is quite important to estimate the amount of air reluctance. This section of the chapter will be focused on analytical solution of the air drag problem. The mathematical expression of the drag force is represented in (3.1):

$$
F_{D}=\frac{C_{D} \rho A V^{2}}{2}
$$

- $\quad$ Air density, average value for current location $\rho=1.2 \mathrm{~kg} / \mathrm{m}^{3}$ [12];

- $\quad V=17.7 \mathrm{~m} / \mathrm{s}$, speed of train [11];

- $\quad$ Drag coefficient of the passenger train $C_{D_{-} \text {train }}=1.8$ [13];

- Drag coefficient of streamlined shelter $C_{D_{-} \text {shelter }}=0.09$ [14];

- Drag coefficient of vertical axis wind turbine $C_{D_{-} \text {turbine }}=0.75$ (see Figure 3.3, consider the blue line, as the shape of blades is flat);

- $\quad$ Frontal area of the train $A=14.44 \mathrm{~m}^{2}$ (see Figure 3.4).

Since the drag force is function of speed squared, it was suggested to use RMS value, however for calculation of the drag the average train speed was used 
since it is larger than RMS in both fast and slow routes $(27 \mathrm{~m} / \mathrm{s}$ against $26.5 \mathrm{~m} / \mathrm{s}$ and $17.7 \mathrm{~m} / \mathrm{s}$ against $16.6 \mathrm{~m} / \mathrm{s}$ respectively).

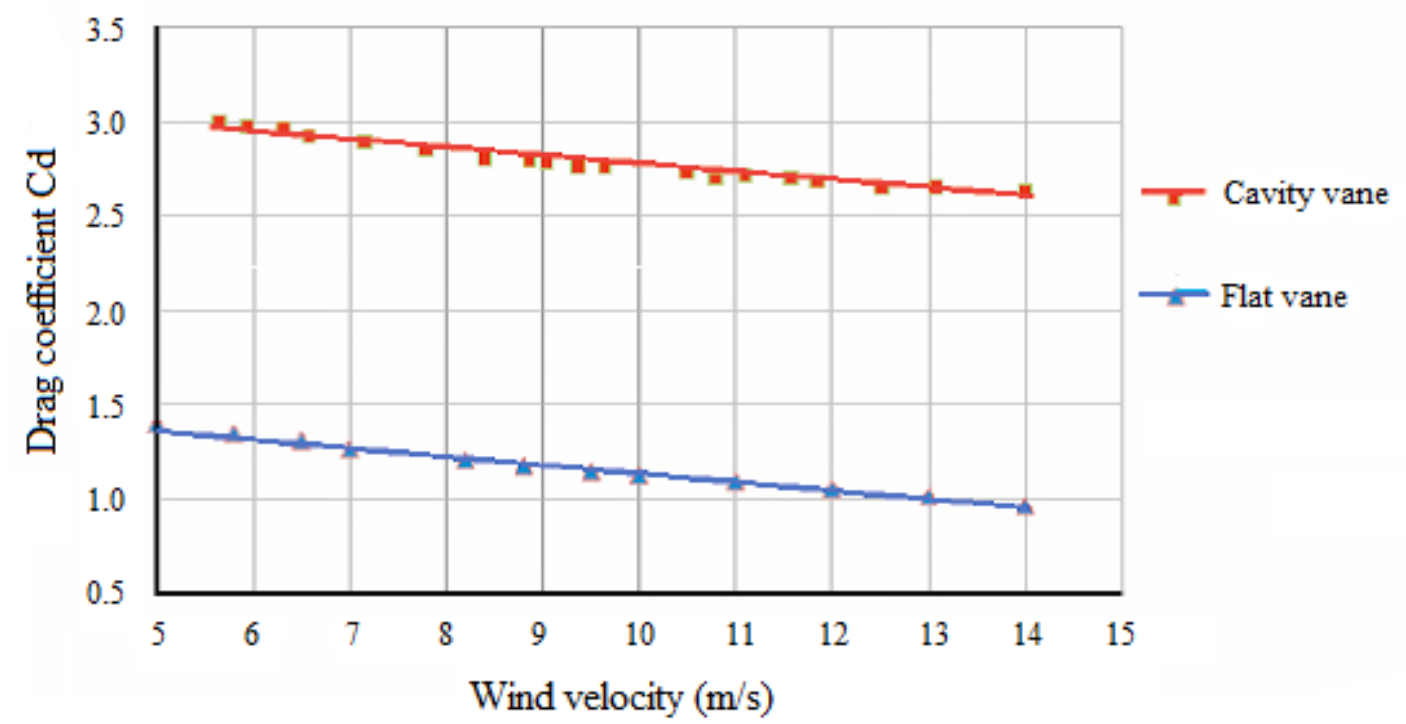

Figure 3. 3: Drag coefficient for different vanes angle in frame vs. wind speed, taken and modified from [15]

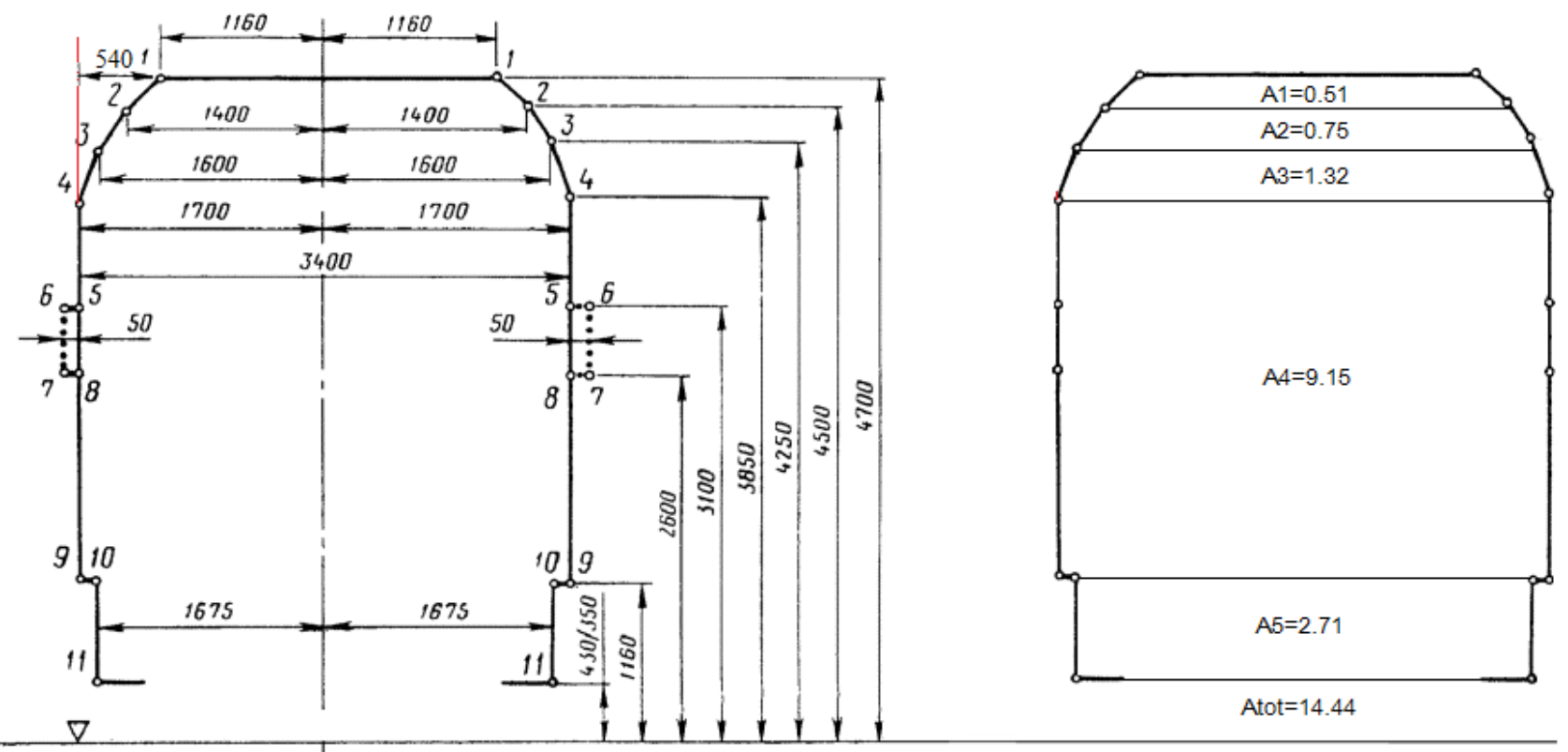

Figure 3. 4: Train frontal area estimation, taken and modified from [24] 
Figure 3.4 shows the frontal view of the wagon and technical characteristics and necessary parameters of the wagon are provided in Table 3.1 [24], while the power consumption of the wagon heating system is basically 54 $\mathrm{kW}$.

Table 3. 1: Technical details of wagon

\begin{tabular}{|c|c|}
\hline \multirow{2}{*}{ Name of the parameters } & Technical parameters \\
\cline { 2 - 2 } & Economy class wagon \\
\hline Length of wagon, meters & 26.7 \\
\hline Width of wagon, meters & 3 \\
\hline Wagon tare weight, tones & 61 \\
\hline Design speed (km/h) & 160 \\
\hline Term of service (years) & 30 \\
\hline Dimension of the wagon according to the GOST 9238 & 1 -VM \\
\hline Sleeping places & 58 \\
\hline Sleeping places for conductors & 1 \\
\hline Cooling performance of air conditioning systems $(\mathrm{kW})$ & 30 \\
\hline Heating system & Combined (water) \\
\hline Electric power supply & Autonomous \\
\hline Converter power (kW) & 32 \\
\hline & \multicolumn{2}{|c|}{ Nominal Power } \\
\hline Boiler heaters of the heating system (kW) & 68 \\
\hline Electric heater (kW) & \\
\hline Generator (kW) & \\
\hline
\end{tabular}


The train frontal area that is facing the air flow was estimated by dividing the actual shape of the front side into several rectangles and trapeziums. The value of drag force exerted on train with no additional installations and power necessary to overcome it are calculated below. In any case, the drag force exerted on train and power necessary to overcome it is:

$$
\begin{gathered}
F_{D_{-} \text {train }}=\frac{1.8 \times 14.4415 \times 1.2 \times 17.7^{2}}{2}=4886 \mathrm{~N} \\
W_{D_{-} \text {train }}=F_{D} \times V=4886 \times 17.7=86.5 \mathrm{~kW}
\end{gathered}
$$

The similar calculation might be conducted for new model by simple summation of drag force on train and streamlined aluminum shelter, since wind turbine, gearbox and generator are all located under it. However, it should be taken into account that the existence of holes or gaps on the surface of the body increases the air reluctance; therefore to consider the worse-case scenario the air drag caused by shelter and wind turbine was calculated separately and then integrated. The gearbox and generator are not included in calculations as they are fully covered by shelter. As it was described in section 3.1 of the current Chapter, the height of the shelter is 0.3 meters and the length is one meter, the wind turbine is 0.6 meters long. That gives the frontal area to be $0.3 \mathrm{~m}^{2}$ and 0.6 $\mathrm{m}^{2}$ respectively. 
Drag force created due to installation of ten items of one meter long shelter and additional power needed to resist it are as follows:

$$
\begin{gathered}
F_{D_{-} \text {shelter }}=\frac{0.09 \times 0.3 \times 1 \times 1.2 \times 17.7^{2}}{2} \times 10=50.8 \mathrm{~N} \\
W_{D_{-} \text {shelter }}=F_{D} \times V=50.75 \times 17.7 \approx 0.9 \mathrm{~kW}
\end{gathered}
$$

Drag force created due to ten items of 0.6 meter long wind turbine and consequent value of power required are obtained as:

$$
\begin{aligned}
& F_{D_{-} \text {turbine }}=\frac{0.75 \times 0.3 \times 0.6 \times 1.2 \times 17.7^{2}}{2} \times 10=253.8 \mathrm{~N} \\
& W_{D_{-} \text {turbine }}=F_{D} \times V=253.8 \times 17.7=4492 \mathrm{~W} \approx 4.5 \mathrm{~kW}
\end{aligned}
$$

As a result, the drag force created due to installation of ten units on top of the train and mechanical power necessary to resist it is as follows:

$$
\begin{gathered}
F_{D_{-} \text {units }}=50.75+253.8=304.6 \mathrm{~N} \\
W_{D_{-} \text {units }}=F_{D} \times V=304.55 \times 17.7 \approx 5.4 \mathrm{~kW}
\end{gathered}
$$

The total drag force exerted on train with ten units installed on the roof and mechanical power required to overcome it are as follows:

$$
\begin{gathered}
F_{D_{-} \text {total }}=4886+304.55 \approx 5.2 \mathrm{kN} \\
W_{D_{-} \text {total }}=F_{D} \times V=5191 \times 17.7 \approx 91.9 \mathrm{~kW}
\end{gathered}
$$


Table 3.2 summarizes the calculations carried out above. It is observed, that the amount of power required to overcome the air resistance increases by $5.9 \%$ with installation of ten units of proposed wind power system.

\section{Table 3. 2: Drag table}

\begin{tabular}{|c|c|c|c|c|c|c|}
\hline Object & $\begin{array}{c}\text { Frontal } \\
\text { area } \\
\left(\mathbf{A}, \mathbf{m}^{\mathbf{2}}\right)\end{array}$ & $\begin{array}{c}\text { Drag } \\
\text { coefficient } \\
\left(\mathbf{C}_{\mathbf{D}}\right)\end{array}$ & $\begin{array}{c}\text { Drag force } \\
\left(\mathbf{F}_{\mathbf{D}}, \mathbf{k N}\right)\end{array}$ & $\begin{array}{c}\text { Power } \\
(\mathbf{P}, \mathbf{k W})\end{array}$ & $\begin{array}{c}\text { Extra } \\
\mathbf{p o w e r} \\
(\mathbf{\Delta P}, \mathbf{k W})\end{array}$ & $\%$ \\
\hline train & 14.4 & 1.8 & 4.9 & 86.5 & - & 0 \\
\hline $\begin{array}{c}\text { train }+ \\
\text { turbine } \\
\text { units }\end{array}$ & 15.0 & 2.4 & 5.2 & 91.9 & 5.4 & 5.9 \\
\hline
\end{tabular}




\section{Chapter 4 - Simulations}

\subsection{Simulation parameters}

It was discussed earlier in Chapter 2, that there are several parameters which have impact on the power output. Therefore, in order to conduct realistic simulations, the number of input values was increased. For instance, since it was decided to simulate the route connecting two Kazakhstani cities Astana (north) and Almaty (south), significant change in altitude has been taken into account.

There are fast and slow train routes running between Astana and Almaty, and the difference is in number of stops (stations) the train performs. The route layout as well as the location of the passenger stations is available from the official website of Kazakhstan Railways and is presented in Figures 4.1 through 4.2, and faster route has 5 passenger stations, while slower route has 11 stations. [11]. 


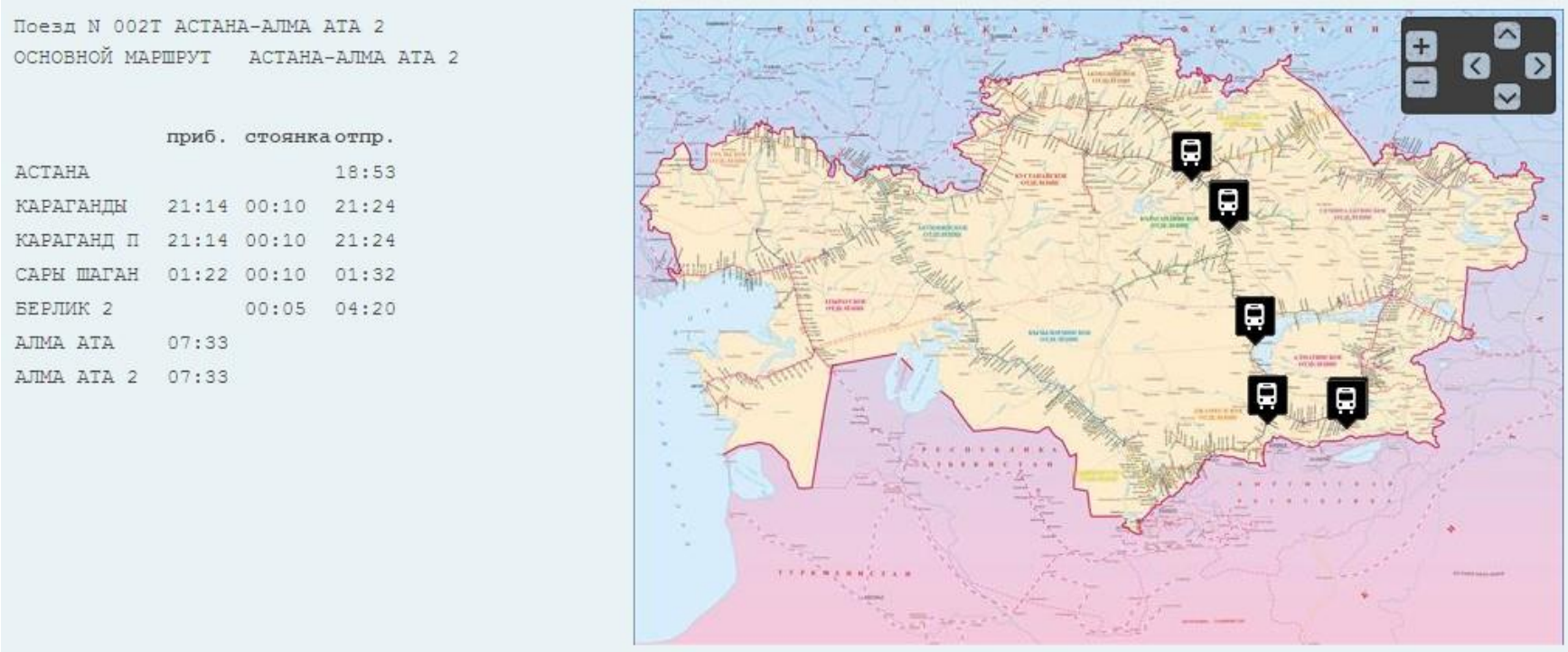

Figure 4. 1: Route (fast) Astana-Almaty on the map of Kazakhstan, taken and modified from [11]

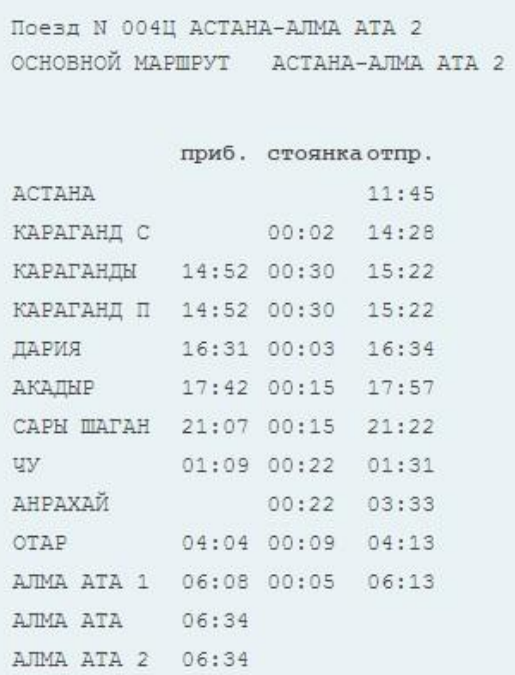

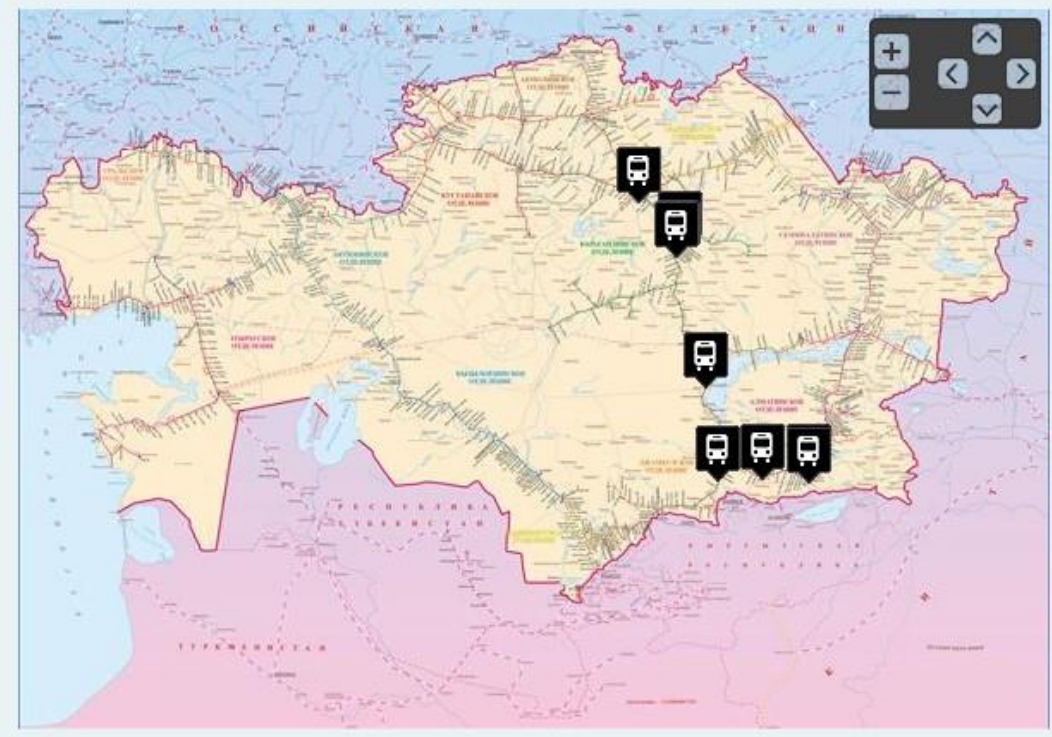

Figure 4. 2: Route (slow) Astana-Almaty on the map of Kazakhstan, taken and modified from [11] 
It should be mentioned that the actual data at specific time points was collected from open sources available. Table 4.2 and Table 4.3 display names of the stations, arrival and stopping time, air temperature at the specific time, air pressure and air density value [12]. All these data will be used as input values in MATLAB Simulink models.

\section{Astana - Almaty $(1200$ km, 5 stations $):$}

- $\quad$ Simulation of route: $04.10 .2016-05.10 .2016$

- $\quad$ Trip duration: 12 hours 40 minutes $=760$ minutes $=45,600$ seconds

- $\quad$ Average speed: $94.7 \mathrm{~km} / \mathrm{h}=27 \mathrm{~m} / \mathrm{s}$

Table 4. 1: Fast trip parameters

\begin{tabular}{|c|c|c|c|c|c|c|c|}
\hline Station & Time & $\begin{array}{c}\text { Length } \\
(\mathbf{H H}: \mathbf{M M})\end{array}$ & $\begin{array}{c}\text { Stop } \\
(\mathbf{m i n})\end{array}$ & \multicolumn{2}{|c|}{$\begin{array}{c}\text { Temperature } \\
\left({ }^{\mathbf{0}} \mathbf{C} / \mathbf{K}\right)\end{array}$} & $\begin{array}{c}\text { Pressure } \\
(\mathbf{k P a})\end{array}$ & $\begin{array}{c}\text { Air } \\
\mathbf{d e n s i t y} \\
\left(\mathbf{k g} / \mathbf{m}^{\mathbf{3}}\right)\end{array}$ \\
\hline Astana & $18: 53$ & - & - & 10.0 & 283.00 & 102.81 & 1.26580 \\
\hline $\begin{array}{c}\text { Karagandy } \\
\text { Pass }\end{array}$ & $21: 14$ & $2: 21$ & 10 & 2.80 & 275.80 & 102.81 & 1.29885 \\
\hline Saryshaghan & $01: 22$ & $3: 58$ & 10 & 6.50 & 279.50 & 102.68 & 1.28000 \\
\hline Berlik 2 & $04: 15$ & $2: 43$ & 5 & 8.75 & 281.75 & 102.27 & 1.26474 \\
\hline Almaty 2 & $07: 33$ & $3: 13$ & - & 5.50 & 278.50 & 102.51 & 1.28250 \\
\hline
\end{tabular}

\section{Astana - Almaty (1200 km, 11 stations):}

- $\quad$ Simulation of route: $04.10 .2016-05.10 .2016$ 
- $\quad$ Trip duration: 18 hours 49 minutes $=1,129$ minutes $=67,740$ seconds

- $\quad$ Average speed: $63.8 \mathrm{~km} / \mathrm{h}=17.7 \mathrm{~m} / \mathrm{s}$

Table 4. 2: Slow trip parameters

\begin{tabular}{|c|c|c|c|c|c|c|c|}
\hline Station & Time & $\begin{array}{c}\text { Length } \\
(\mathbf{H H}: \mathbf{M M})\end{array}$ & $\begin{array}{c}\text { Stop } \\
(\mathbf{m i n})\end{array}$ & \multicolumn{2}{|c|}{$\begin{array}{c}\text { Temperature } \\
\left({ }^{\mathbf{}} \mathbf{C} / \mathbf{K}\right)\end{array}$} & $\begin{array}{c}\text { Pressure } \\
(\mathbf{k P a})\end{array}$ & $\begin{array}{c}\text { Air } \\
\mathbf{d e n s i t y} \\
\left(\mathbf{k g} / \mathbf{m}^{\mathbf{3}}\right)\end{array}$ \\
\hline Astana & $11: 45$ & - & - & 10.5 & 283.50 & 102.81 & 1.2636 \\
\hline $\begin{array}{c}\text { Karagandy } \\
\text { Sort }\end{array}$ & $14: 26$ & $2: 41$ & 2 & 11.0 & 284.00 & 102.81 & 1.2613 \\
\hline $\begin{array}{c}\text { Karagandy } \\
\text { Pass }\end{array}$ & $14: 52$ & $0: 24$ & 30 & 11.0 & 284.00 & 102.81 & 1.2613 \\
\hline Dariya & $16: 31$ & $1: 09$ & 3 & 11.5 & 284.50 & 102.95 & 1.2608 \\
\hline Akadyr & $17: 42$ & $1: 08$ & 15 & 11.3 & 284.30 & 102.91 & 1.2612 \\
\hline Saryshaghan & $21: 07$ & $3: 10$ & 15 & 8.88 & 281.88 & 102.68 & 1.2692 \\
\hline Chu & $01: 09$ & $3: 47$ & 22 & 7.85 & 280.85 & 102.44 & 1.2709 \\
\hline Anrakhay & $03: 11$ & $1: 40$ & 22 & 1.82 & 274.82 & 102.61 & 1.3000 \\
\hline Otar & $04: 04$ & $0: 31$ & 9 & 3.00 & 276.00 & 102.57 & 1.2949 \\
\hline Almaty 1 & $06: 08$ & $1: 55$ & 5 & 4.87 & 277.87 & 102.51 & 1.2854 \\
\hline Almaty 2 & $06: 34$ & $0: 21$ & - & 4.87 & 277.87 & 102.51 & 1.2854 \\
\hline
\end{tabular}

Since the time parameter is measured in seconds, the corresponding simulation times for fast and slow route in Simulink are 45,600 and 67,740 seconds respectively. As the meteorological data is available at exactly specific train station at certain time point, the air temperature and density values for intermediate locals were estimated through mathematical interpolation method. 


\subsection{MATLAB and SolidWorks simulations}

The proposed model was built in several software environments. The conceptual design itself was created using AutoCAD and was already covered in the beginning of the current Chapter, while aerodynamic flow analysis was conducted in SolidWorks, and the simulation of the whole system was carried out using MATLAB Simulink.

The detailed drawings of the conceptual model as well as the projected views are provided in Appendix A. The aerodynamic simulation results including tables and graphs, and the air flow trajectories indicating the velocity profile at the surface of the model can be observed in Appendix B.

Figure 4.3 illustrates the MATLAB Simulink model of the system. It should be mentioned, that wind speed and air density are variables that change over the time, and are presented as matrices. The MATLAB code was written in order to create these matrices and convert them into Simulink readable .mat files (see Appendix C).

Basically, the wind speed and air density are both $m \times 2$ matrices, where $\mathrm{m}$ is the duration of the trip in seconds. Since the longest route Astana-Almaty is 67740 seconds, such matrices are quite challenging for MATLAB and Simulink 
to process. On the other hand, the route Astana-Aktau is approximately equal to 1 day 21 hours 45 minutes, which is equal to 164,700 seconds.

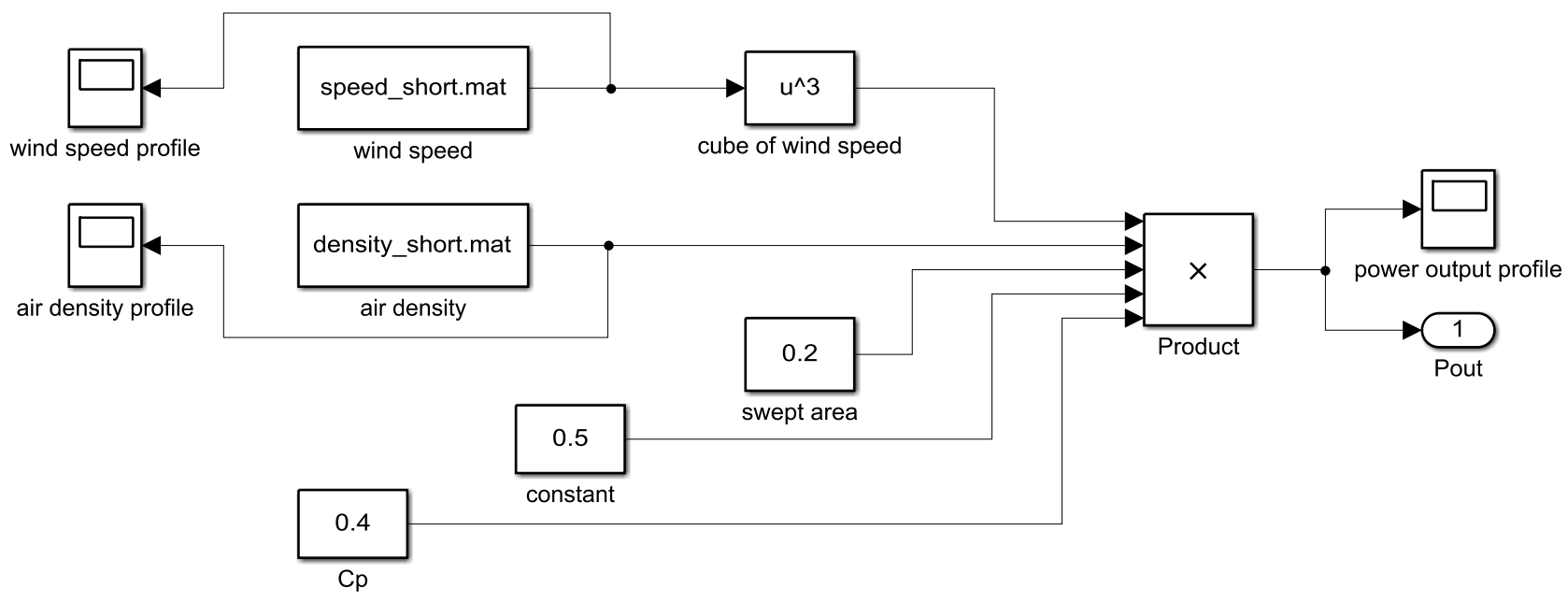

Figure 4. 3: MATLAB Simulink model

The flow simulations are illustrated in Figures 4.4 through 4.5. In general, two sets of air flow analysis were conducted. Firstly, simple wagon with no installations was put in improvised air tunnel in SolidWorks environment and the horizontal component of the force was measured. Afterwards, ten units of wind power system were allocated accordingly and the similar flow test was carried out. Since the train movement is in X-direction, correspondingly the $\mathrm{X}$ component of the drag force was estimated and noted. It was expected that the analytical and simulated values of drag coefficient and drag force will not be similar. Therefore, it was decided to focus on percentage value by which the drag force will increase when ten units are installed on the roof. 


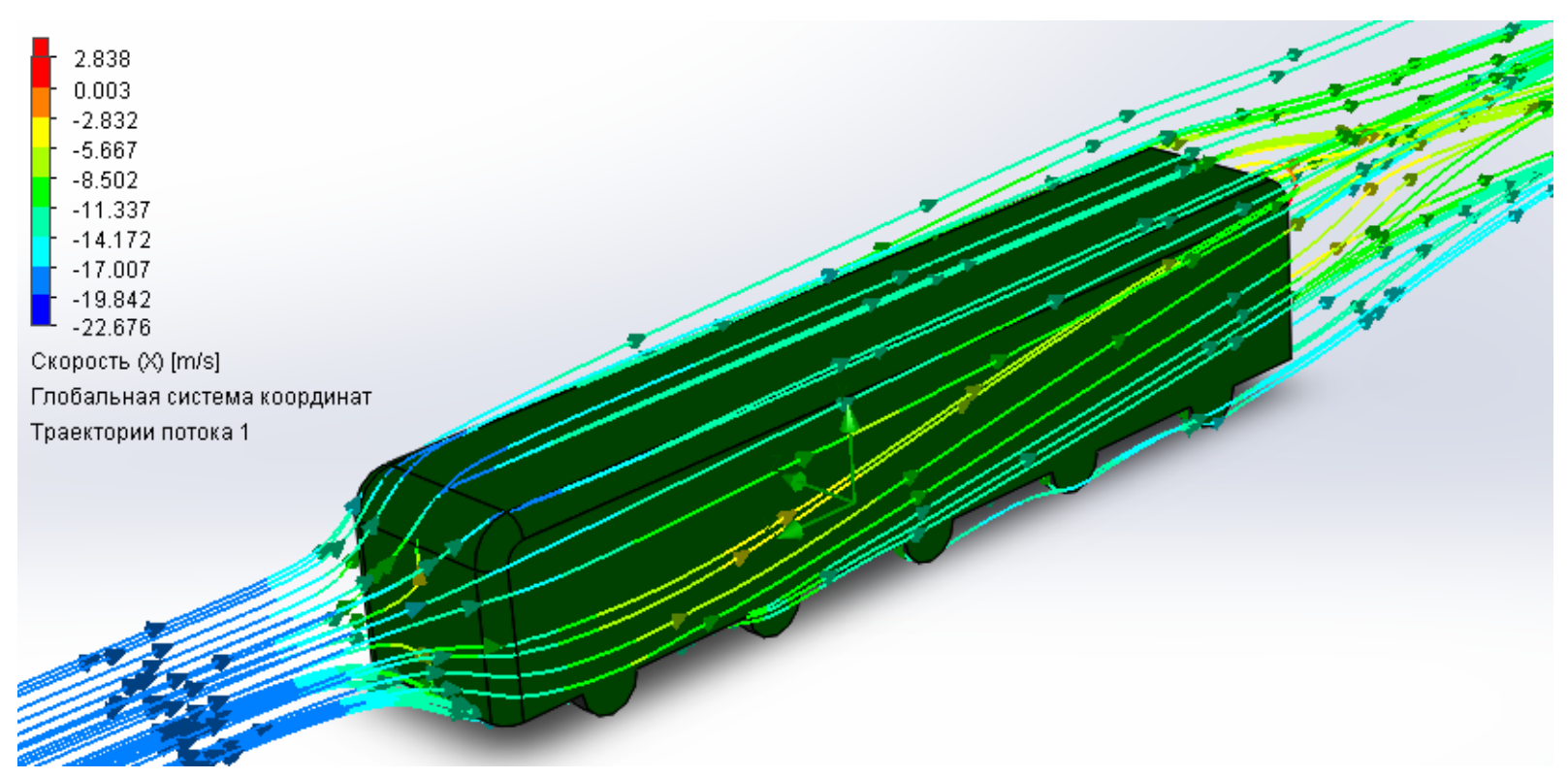

Figure 4. 4: SolidWorks flow simulation for simple wagon

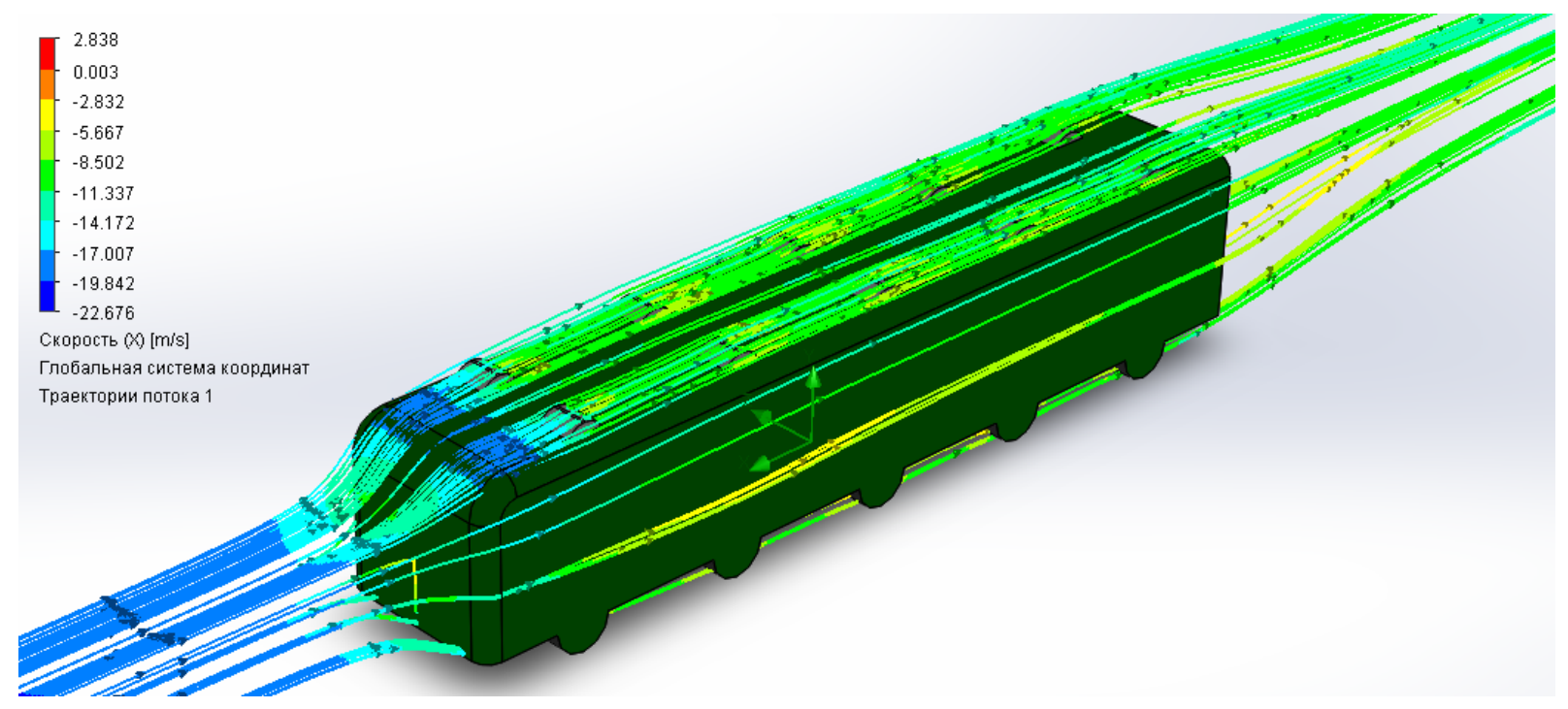

Figure 4. 5: SolidWorks flow simulation for wagon with turbines

From the flow simulation presented it is observable that the air flow is more intense with ten units installed on the train. This is beneficial due to fact that the denser air flow going through the designed duct on the shelter will tend to increase of wind speed (for air flow trajectories for different turbine 
allocations see Appendix B). On the other hand, the wind speeds at the inlets of the improvised ducts are similar. In order to maintain the accuracy of simulations, the solver field parameters were not changed for both geometries.

The net force is estimated to be $13,828 \mathrm{~N}$ and $14,034 \mathrm{~N}$ for simple wagon and for wagon with ten wind power units installed, and this difference is result of additional air drug caused by wind power unit. For detailed SolidWorks flow simulation results including data tables, graphs and force distribution also refer to Appendix B. 


\section{Chapter 5 - Results and Discussions}

\subsection{Software simulation results}

The wind speed, air density and generated output power are displayed in Figures 5.1 through 5.6. Unlike air density which does not fluctuate significantly, change in wind speed has a notable impact on output power value. Nevertheless, the air density varies in range between nearly $1.26-1.3 \mathrm{~kg} / \mathrm{m}^{3}$ for both routes.

Due to absence of information from continuous monitoring of train speed, $27 \mathrm{~m} / \mathrm{s}$ and $17.7 \mathrm{~m} / \mathrm{s}$ were taken as maximum wind speed for fast and slow routes accordingly, whereas currently used trains are capable of reaching the velocity of about $35 \mathrm{~m} / \mathrm{s}$.

The acceleration and deceleration values of $0.5 \mathrm{~m} / \mathrm{s}^{2}$ and $0.3 \mathrm{~m} / \mathrm{s}^{2}$ for fast and slow routes, necessary stopping distance were assumed based on standards and according to train's moving speed and length [24]. The time required for train to start deceleration and stop is calculated as follows:

$$
\begin{aligned}
& t_{\text {stop }}=\frac{27 \mathrm{~m} / \mathrm{s}}{0.5 \mathrm{~m} / \mathrm{s}^{2}}=54 \mathrm{~s} \text { (fast route) } \\
& t_{\text {stop }}=\frac{17.7 \mathrm{~m} / \mathrm{s}}{0.3 \mathrm{~m} / \mathrm{s}^{2}}=59 \mathrm{~s}(\text { slow route) }
\end{aligned}
$$


From MATLAB simulation the power coefficient of the wind turbine was obtained to be 0.4 (Appendix C). The output power profiles display the power at the turbine output, and its average value during train movement is equal to $1005 \mathrm{~W}$ for fast route and $285 \mathrm{~W}$ for slow route respectively. These are energy generated during one hour of operation, and the net power is basically calculated by multiplying these numbers by duration of the trip. Total power calculations are presented in next section of this chapter.

However, it should be noted that during stop times the power at the turbine output will become zero. On the other hand, there is a possibility to implement a supplementary device which will inject air directed to turbine blade from compressed air storage, and will maintain a stable and continuous power output. Nevertheless, this is out of the scope of this thesis and is subject for further studies. 


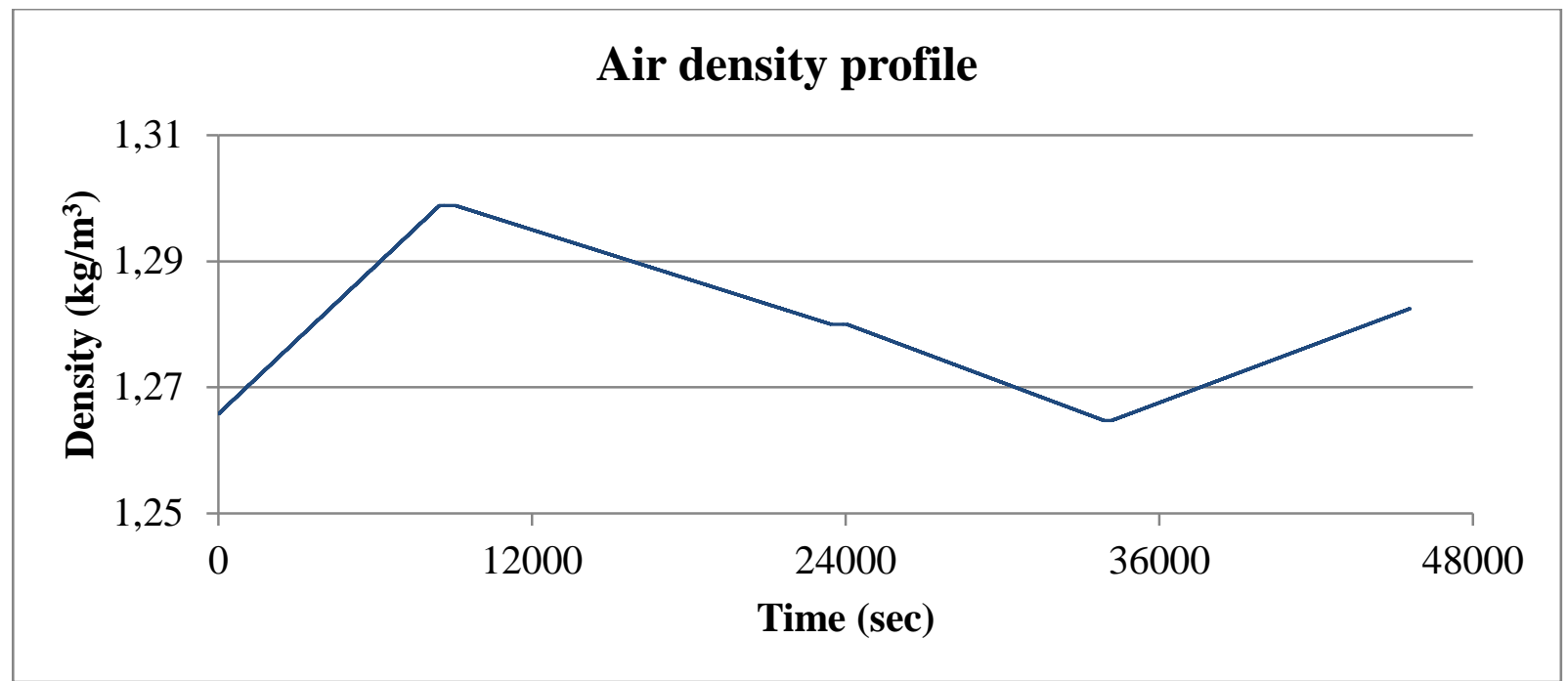

Figure 5. 1: Air density profile for fast route

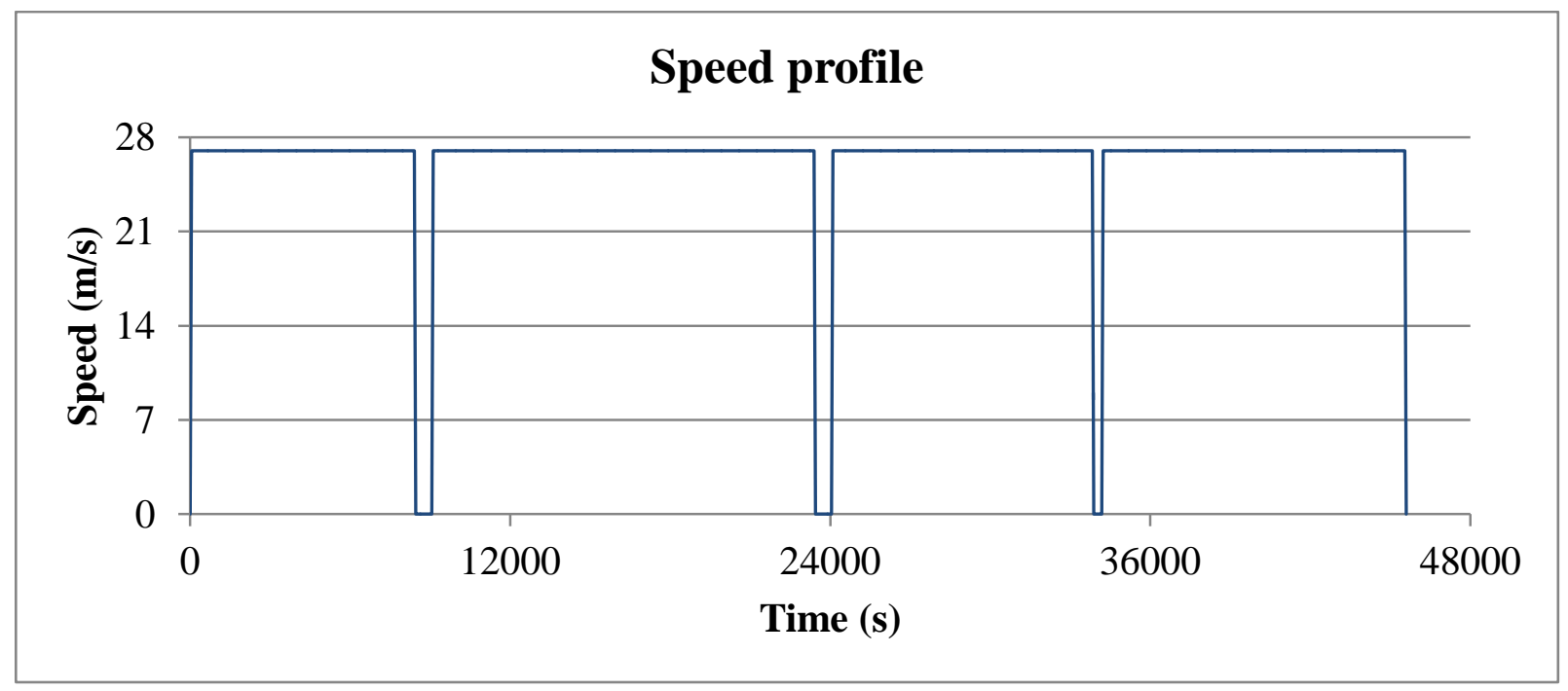

Figure 5. 2: Speed profile for fast route 


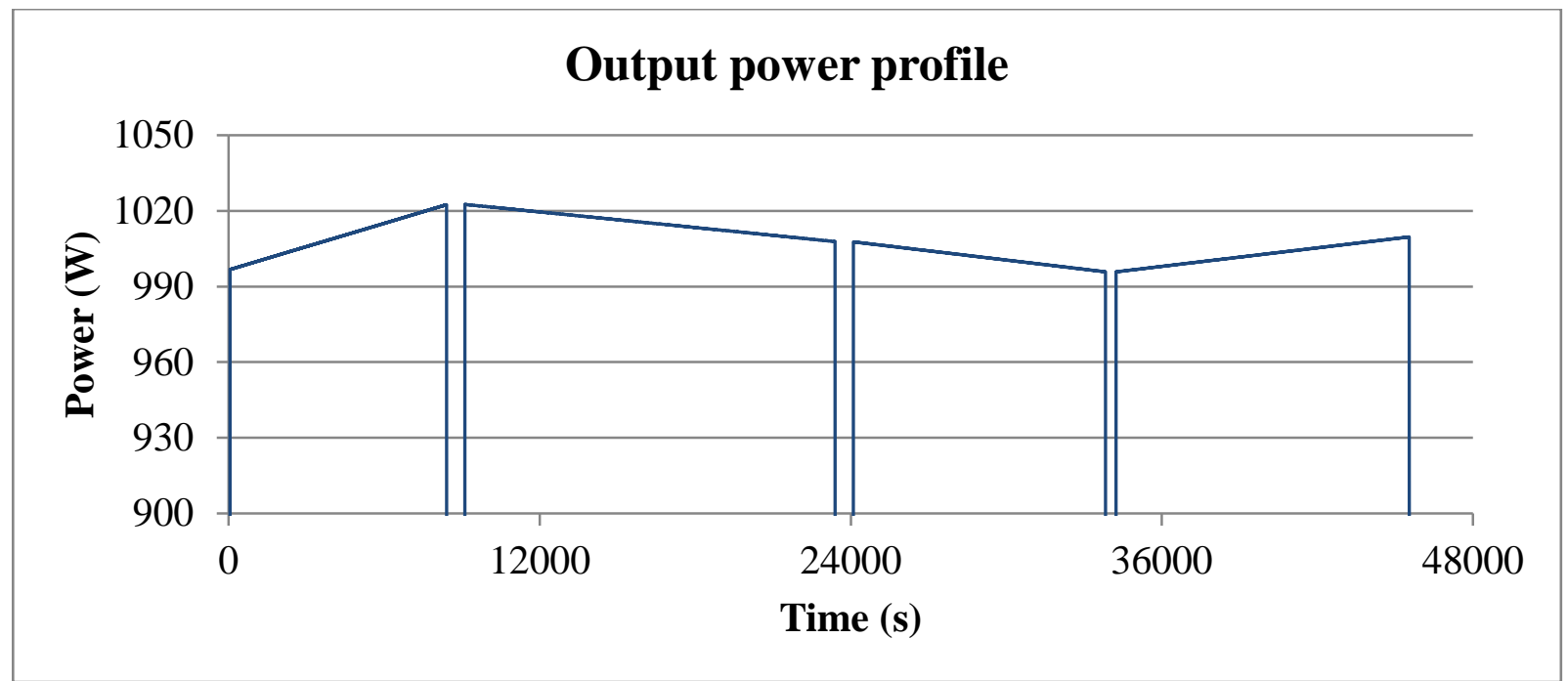

Figure 5. 3: Output power profile for fast route

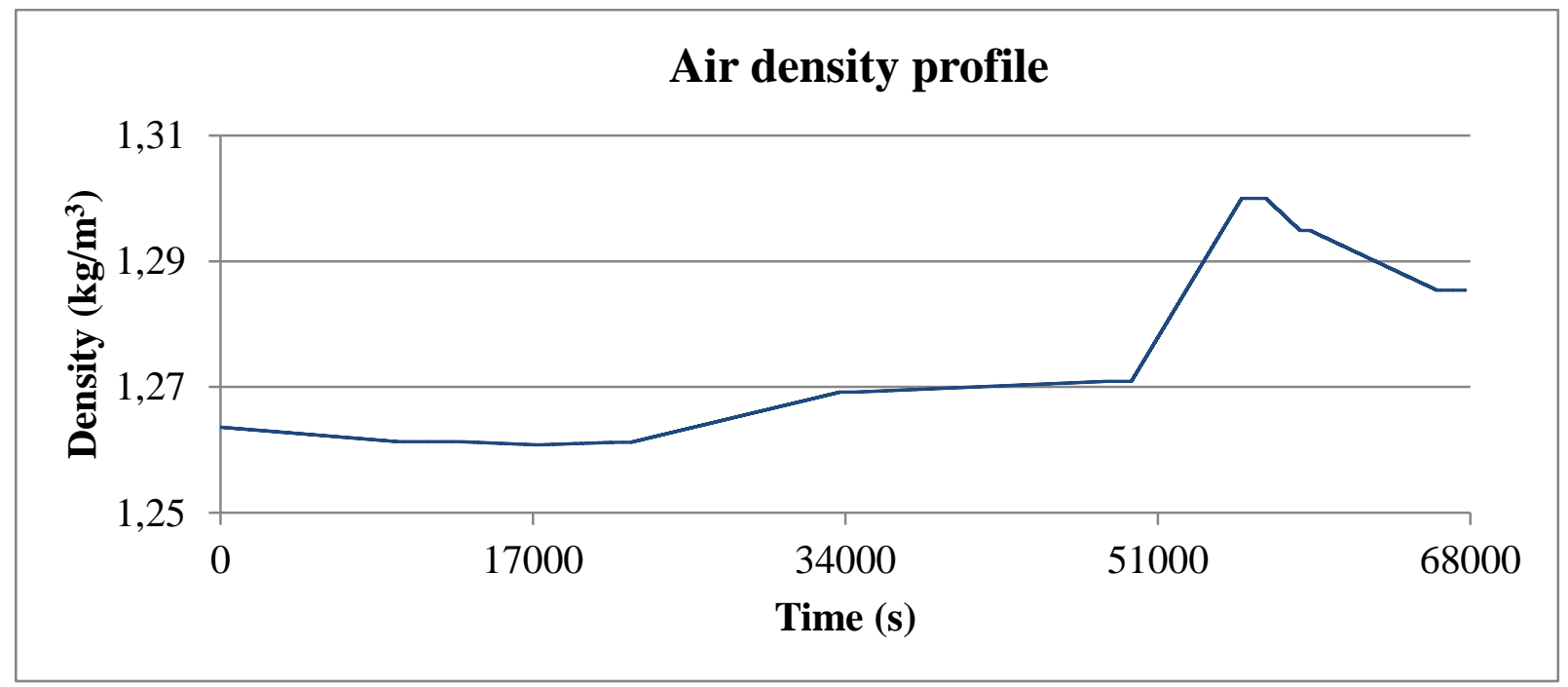

Figure 5. 4: Air density profile for slow route 


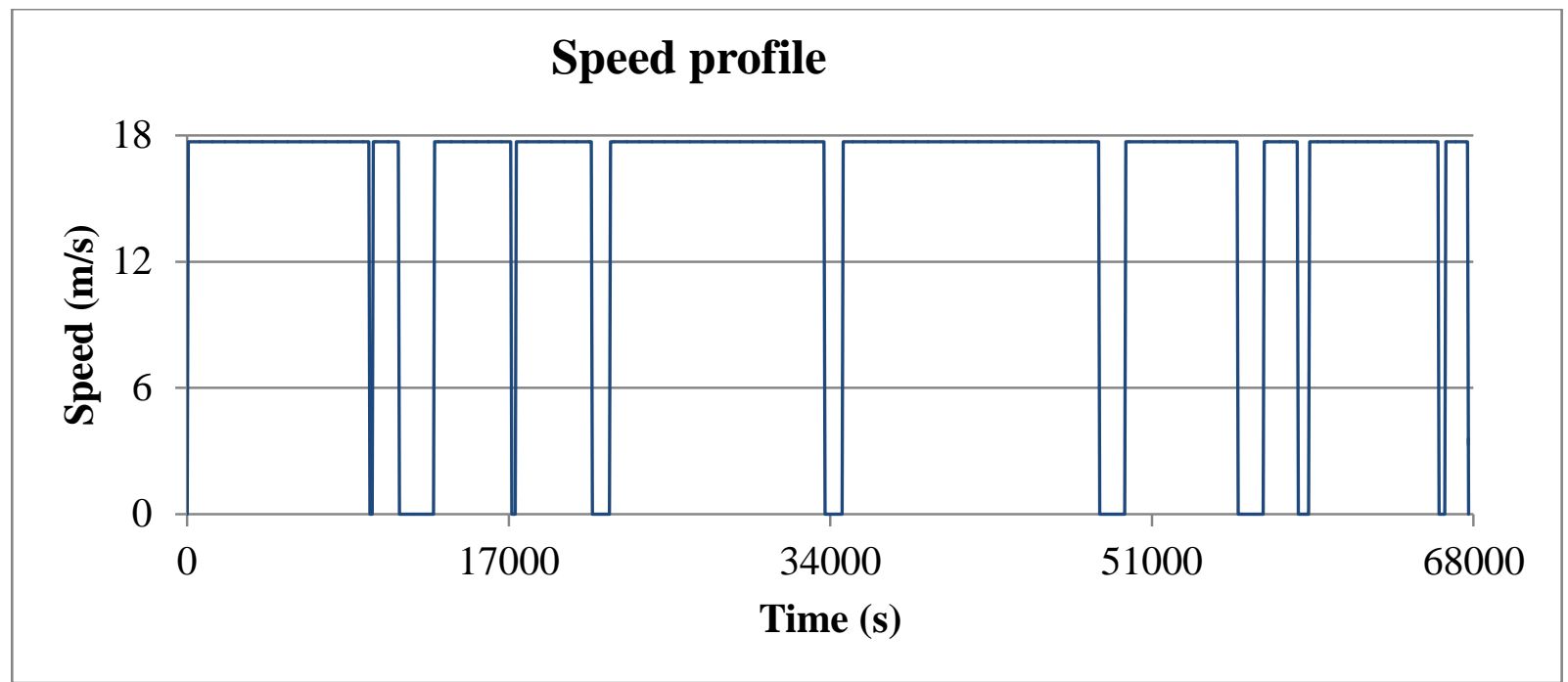

Figure 5. 5: Air speed profile for slow route

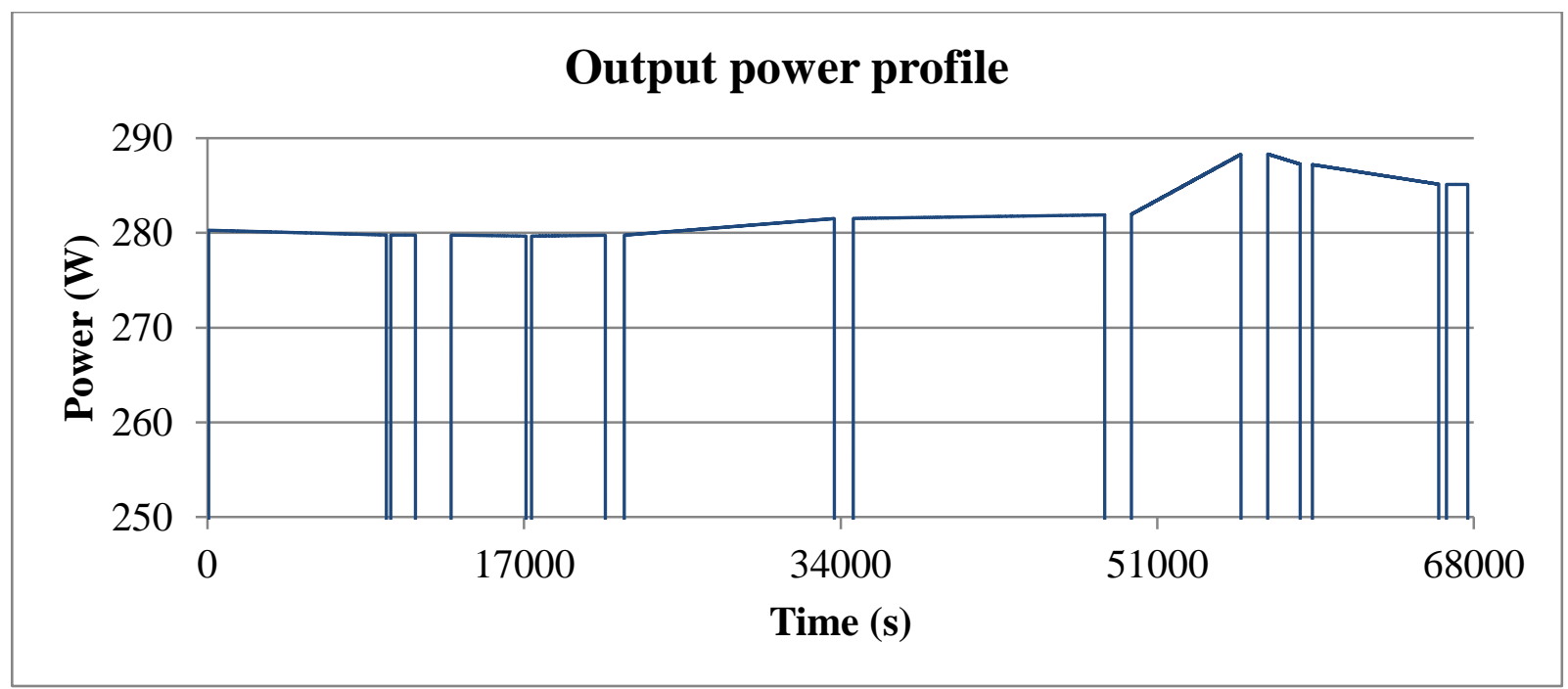

Figure 5. 6: Output power profile for slow route

The comparison between actual and simulated wind speed for the trip between stations Astana and Karagandy Pass is illustrated in Figure 5.7 and Figure 5.8. It can be observed that the acceleration and deceleration rates are smaller than simulated ones, hence it takes longer time to reach the maximum 
and minimum speed. Moreover, the speed fluctuations were neglected during simulation of the routes, since some internal and external factors such as train turning and manual speed control were not included.

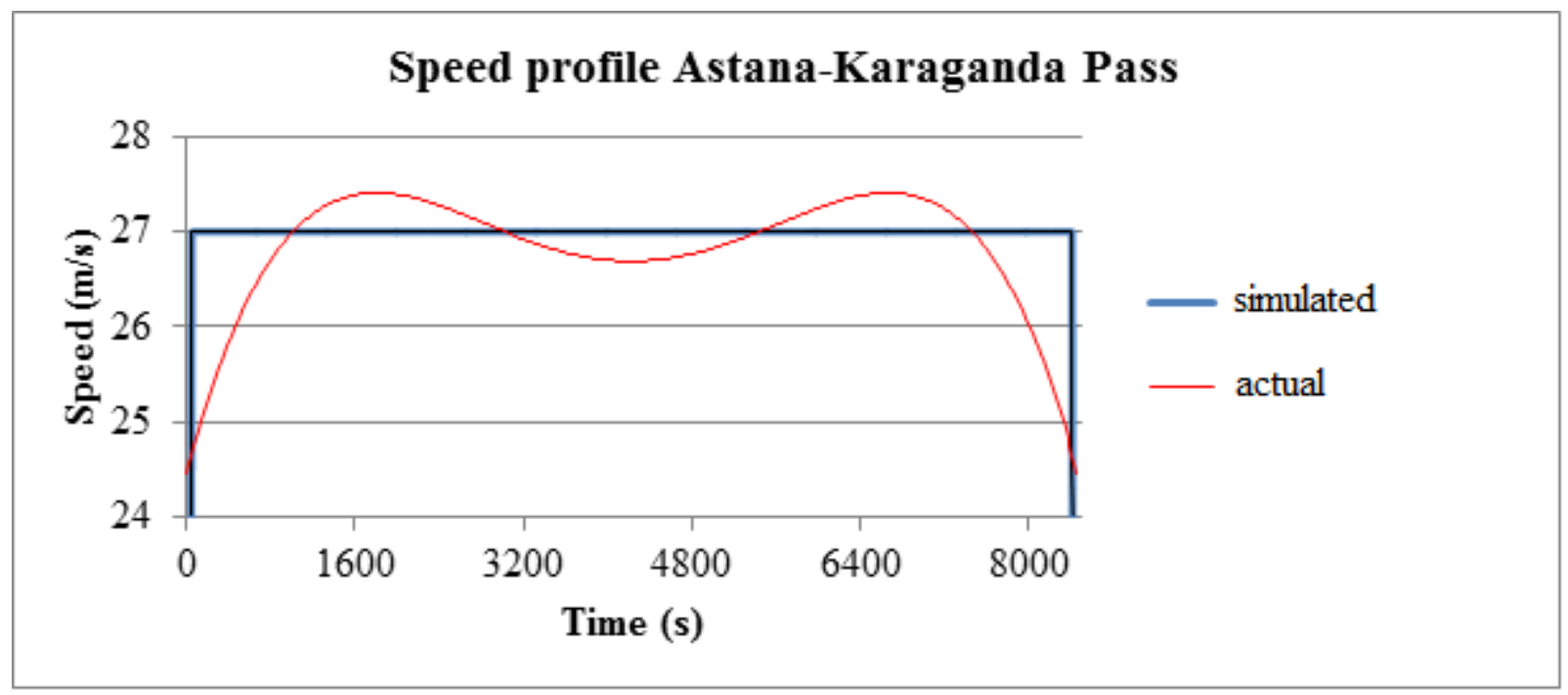

Figure 5. 7: Air speed profiles comparison for fast route

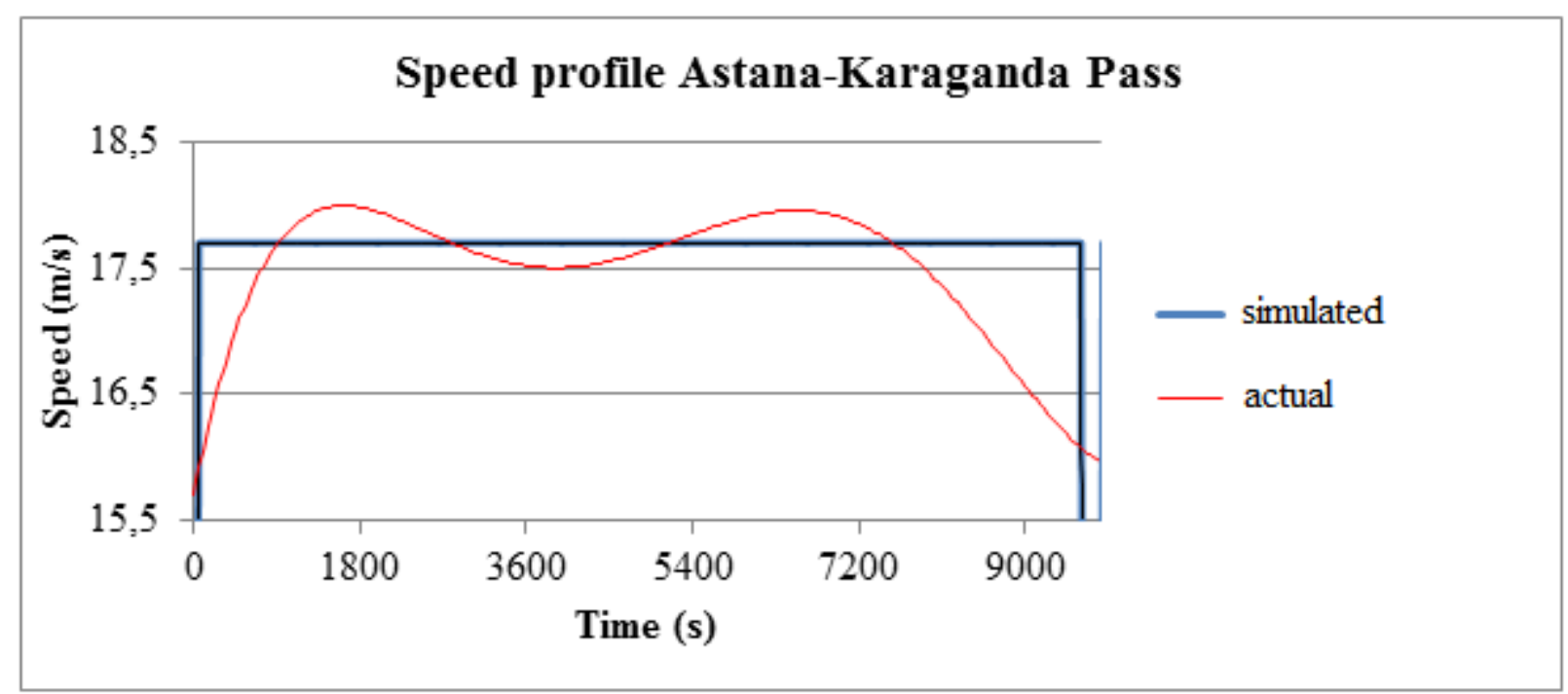

Figure 5. 8: Air speed profiles comparison for slow route

The measured values for estimation of additional drag are presented in Table 5.1, whereas the detailed set of data is available in Appendix B. The 
increase in pressure is expected since the surface area facing the air flow is larger in second case. However, it is notable that the drag force increased by slightly $1.5 \%$ for total force and by $2.8 \%$ for surface force, whereas analytical estimation has shown $5.9 \%$ rise. Nevertheless, during the mathematical solution of the problem the worst case scenario was assumed. In addition, the air density values used for analytical and software simulation were constant and variable respectively.

Discrepancy between software and numerical solutions of additional drag can be explained by the fact that the drag coefficient for train, wind turbine, and shelter used in calculations were not estimated experimentally for the specific solids, but taken from the existing literature, whereas SolidWorks simulations considered the shape and materials used for every part of the model.

Table 5. 1: SolidWorks data for flow simulation

\begin{tabular}{|c|c|c|}
\hline Local parameter & Wagon & Wagon + turbine units \\
\hline Pressure (Pa) & 101642.4 & 101642.6 \\
\hline Total force (N) & 13828 & 14034 \\
\hline Surface force (N) & 10251 & 10546 \\
\hline Increase in force & \multicolumn{2}{|c|}{$\begin{array}{c}1.5 \% \text { for total force } \\
2.8 \% \text { for surface force }\end{array}$} \\
\hline
\end{tabular}




\subsection{Wind turbine output power}

In any case, even if ten units are installed on train, the output power per one-way trip will be $126.7 \mathrm{~kW}$ and $56.5 \mathrm{~kW}$ for fast and slow route respectively. Noting that these amount of power are enough to overcome on air drag and also supply energy to the load.

In industry it is customary to express the electrical power in per units. Therefore, in order to make the comparison of the power output for different cases, it was decided to take the power of one turbine per entire train as a reference.

Output power during one trip if one turbine is installed on entire train:

Astana-Almaty (fast) $-1 \mathrm{~kW} / \mathrm{h} \times 12.67 \mathrm{~h}=12.67 \mathrm{~kW}=1$ p.u.

Astana-Almaty (slow) $-0.3 \mathrm{~kW} / \mathrm{h} \times 18.82 \mathrm{~h}=5.65 \mathrm{~kW}=0.45$ p.u.

Output power during one trip if ten turbines are installed on train:

Astana-Almaty (fast) $-10 \mathrm{~kW} / \mathrm{h} \times 12.67 \mathrm{~h}=126.7 \mathrm{~kW}=10$ p.u.

Astana-Almaty (slow) $-3 \mathrm{~kW} / \mathrm{h} \times 18.82 \mathrm{~h}=56.46 \mathrm{~kW}=4.46$ p.u. 


\section{Output power during one trip if ten turbines are installed on each}

wagon:

Astana-Almaty (fast) $-10 \mathrm{~kW} / \mathrm{h} \times 25 \times 12.67 \mathrm{~h}=3.17 \mathrm{MW}=250.2$ p.u.

Astana-Almaty (slow) $-3 \mathrm{~kW} / \mathrm{h} \times 25 \times 18.82 \mathrm{~h}=1.41 \mathrm{MW}=111.3$ p.u.

\subsection{Economical and Environmental Profit}

The profit from the proposed model might be considered from several prospective:

- Fuel economy;

- Carbon dioxide emission reduction;

- Taxes for greenhouse gas emission.

According to information provided by JSC National Company Kazakhstan Temirzholy, there are currently 550 locomotives in total and 250 in service available. Financial profit of installing ten units on train is presented in Tables 5.2 and Table 5.3. However, it is recommended to primarily familiarize with the following conversions:

- $\quad$ Cost of the fuel: 1 ton of diesel $=28.56$ gallons $=14,600 \mathrm{KZT}[11]$;

- $\quad$ Carbon dioxide emission: 1 gallon of diesel $=10.15 \mathrm{~kg}$ of $\mathrm{CO}_{2}$ [25]; 
- Taxes for carbon dioxide emission: 1 ton of $\mathrm{CO}_{2}=135 €=$ $135 \times 374.54=50,563$ KZT [26];

- Electrical power to amount of fuel equivalency: $600 \mathrm{kWh} /$ day $=$ 12.28 gallon of diesel $=0.43$ ton of diesel $=126.93 \mathrm{~kg}$ of $\mathrm{CO}_{2}$;

- $\quad$ Fuel economy per day: 0.43 ton of diesel = 6,278 KZT/day;

- $\quad$ Profit from carbon dioxide emission decrease: $126.93 \mathrm{~kg}$ of $\mathrm{CO}_{2}=$ $6,418 \mathrm{KZT} / \mathrm{day}$.

Basically, the power output per single trip from the ten units installed on each wagon of all trains available on service will be approximately equal to 3.17 MW and 1.41 MW for fast and slow routes respectively. Table 5.2 shows that for the fast route annual profit will be $\$ 87,000$ if wind power generation unit is implemented on only one train (250 turbines in total) and $\$ 21,840,000$ if units are mounted on all 250 trains in service $(62,500$ turbines in total). Similarly, Table 5.3 shows that for the slow route financial gain per annum will be approximately $\$ 39,000$ and $\$ 9,700,000$ for one train and all trains in service respectively. 
Table 5. 2: Financial gain for the fast route

\begin{tabular}{|c|c|c|c|c|}
\hline \multicolumn{5}{|c|}{ 3.17 MW output power } \\
\hline \multirow{2}{*}{\multicolumn{2}{|c|}{250 turbines }} & \multirow{2}{*}{$\begin{array}{l}\text { Saved amount } \\
\text { (tons) }\end{array}$} & \multicolumn{2}{|c|}{ Economy } \\
\hline & & & KZT & USD \\
\hline \multicolumn{2}{|c|}{ Diesel } & 2.73 & 39,823 & 119.43 \\
\hline \multicolumn{2}{|c|}{$\mathrm{CO}_{2}$} & 0.79 & 40,000 & 119.96 \\
\hline \multirow{2}{*}{ Total } & $/$ day & & 80,000 & 240 \\
\hline & /year & & $29,000,000$ & 87,000 \\
\hline \multicolumn{5}{|c|}{ 3.17 MW output power } \\
\hline \multirow{2}{*}{\multicolumn{2}{|c|}{62,500 turbines }} & Saved amount & \multicolumn{2}{|c|}{ Economy } \\
\hline & & (tons) & KZT & USD \\
\hline \multicolumn{2}{|c|}{ Diesel } & 681.90 & $9,955,750$ & 29,858 \\
\hline \multicolumn{2}{|c|}{$\mathrm{CO}_{2}$} & 197.65 & $10,000,000$ & 29,991 \\
\hline \multirow{2}{*}{ Total } & /day & & $20,000,000$ & 60,000 \\
\hline & /year & & $7,300,000,000$ & $21,840,000$ \\
\hline
\end{tabular}

Table 5. 3: Financial gain for the slow route

\begin{tabular}{|c|c|c|c|c|}
\hline \multicolumn{5}{|c|}{1.41 MW output power } \\
\hline \multirow{2}{*}{\multicolumn{2}{|c|}{250 turbines }} & \multirow{2}{*}{$\begin{array}{l}\text { Saved amount } \\
\text { (tons) }\end{array}$} & \multicolumn{2}{|c|}{ Economy } \\
\hline & & & KZT & USD \\
\hline \multicolumn{2}{|c|}{ Diesel } & 1.21 & 17,713 & 53.12 \\
\hline \multicolumn{2}{|c|}{$\mathrm{CO}_{2}$} & 0.35 & 17,792 & 53.36 \\
\hline \multirow{2}{*}{ Total } & /day & & 36,000 & 106 \\
\hline & /year & & $13,000,000$ & 39,000 \\
\hline \multicolumn{5}{|c|}{ 1.41 MW output power } \\
\hline \multirow{2}{*}{\multicolumn{2}{|c|}{ 62,500 turbines }} & Saved amount & \multicolumn{2}{|c|}{ Economy } \\
\hline & & (tons) & KZT & USD \\
\hline \multicolumn{2}{|c|}{ Diesel } & 303.3 & $4,428,250$ & 13,281 \\
\hline \multicolumn{2}{|c|}{$\mathrm{CO}_{2}$} & 87.93 & $4,448,000$ & 13,340 \\
\hline \multirow{2}{*}{ Total } & /day & & $9,000,000$ & 27,000 \\
\hline & /year & & $3,240,000,000$ & $9,700,000$ \\
\hline
\end{tabular}




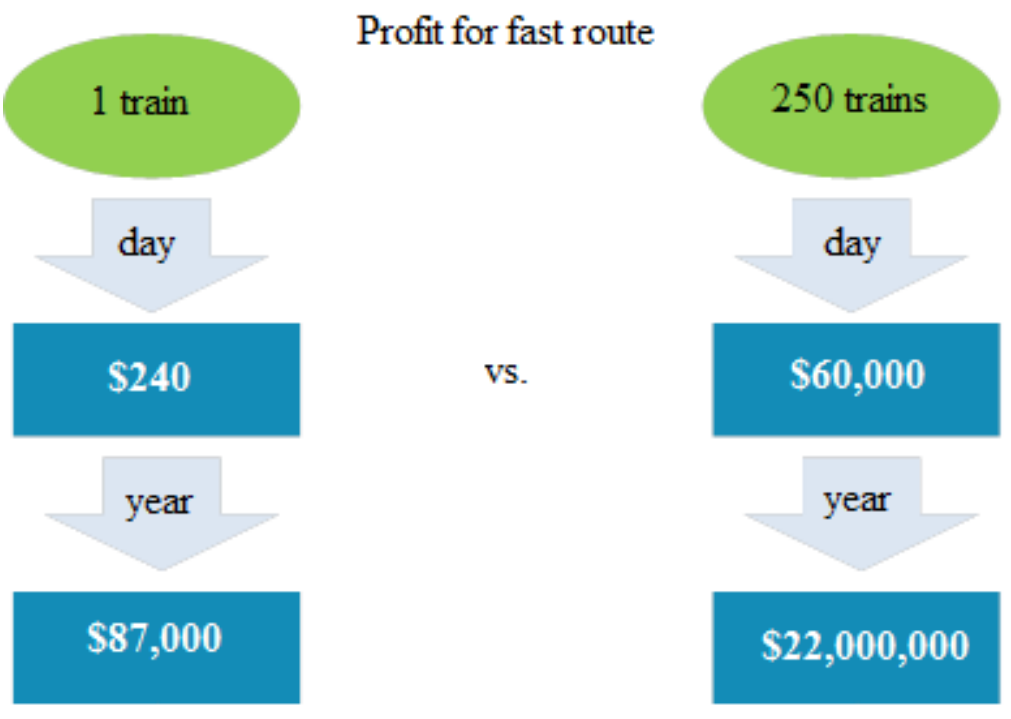

Figure 5. 9: Comparison of financial gain for fast route

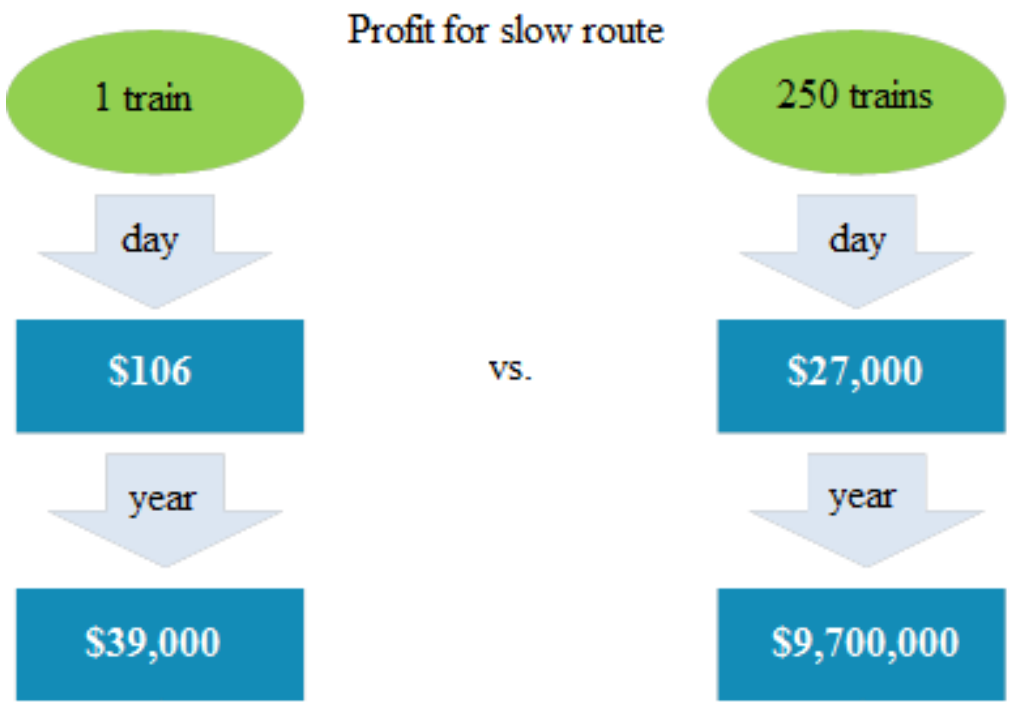

Figure 5. 10: Comparison of financial gain for slow route

Figure 5.9 and Figure 5.10 summarize the economical profit of proposed model for fast and slow routes. The annual profit for the fast route is approximately 2.3 times higher compared to slow route. 
In case the wind power system is implemented in both types of trains (fast and slow route), the annual income will be $\$ 126,000$ and $\$ 31,700,000$ for single train and for all trains currently in service, respectively.

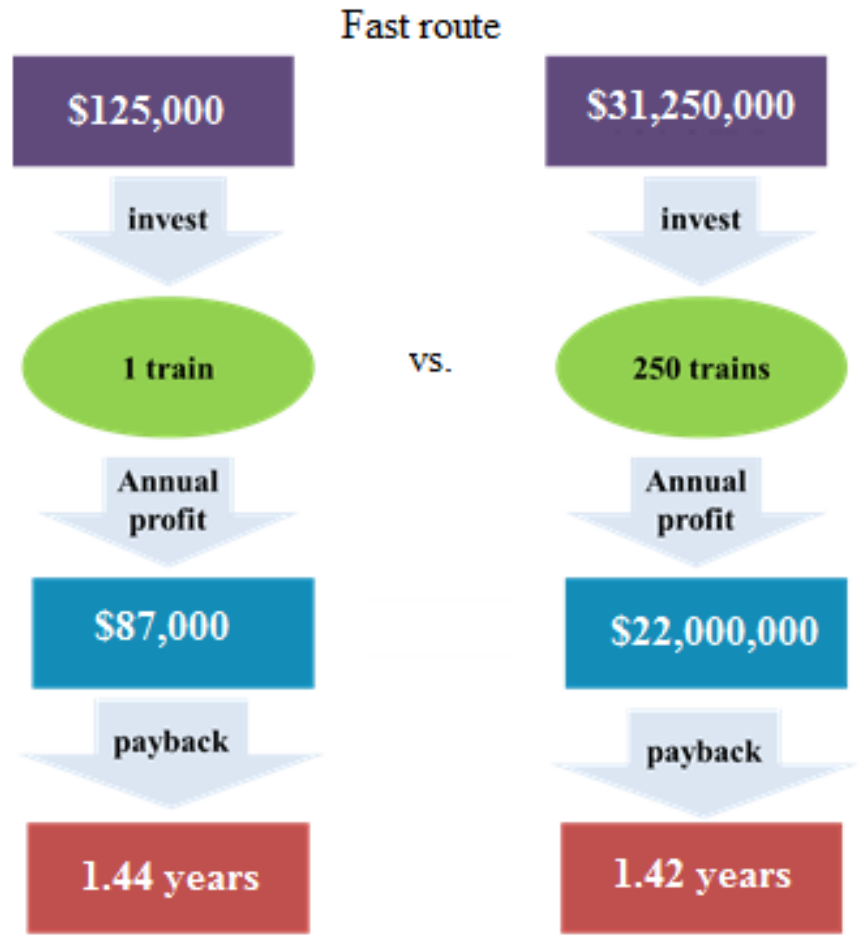

Figure 5. 11: Payback period for fast route 
Slow route

\section{$\$ 125,000$}

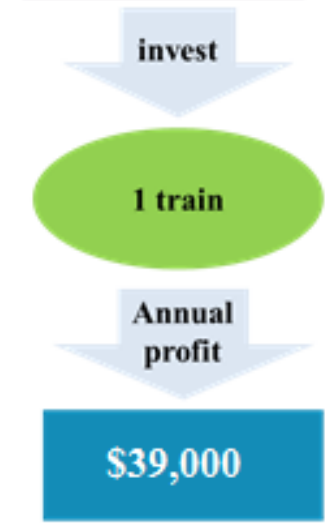

payback

3.21 years

\section{$\$ 31,250,000$}

invest

vs.

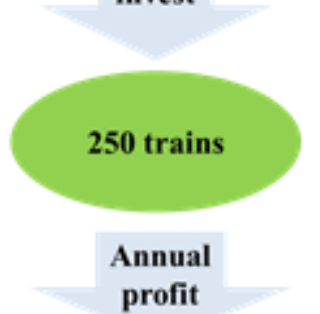

$\$ 9,700,000$

payback

3.22 years

Figure 5. 12: Payback period for slow route

Figure 5.11 and Figure 5.12 demonstrate the payback period for different scenario. The cost of single wind power unit is estimated at approximately $\$ 500$, and for ten units on single train consisting of 25 wagons it will cost $\$ 125,000$ in total. The notable fact is that the cashback time is quite reasonable for both cases. Moreover, in case of slow route trains were integrated with wind power system, the investment made will be recovered in slightly more than 3 years. This numbers are promising and enthusiastic for renewable energy project. 


\section{Chapter 6 - Conclusions and Future Work}

The scope of this Thesis was to conduct the feasibility study on implementation of wind energy system on moving trains. Suggested model was examined in several prospective. At first, the overall power generation capability of the wind energy unit was estimated. Afterwards, the mechanical challenges caused by installation of the unit on top of the train were analyzed both mathematically and through simulation. Finally, the ecological and economical assets that might be gained in the result of realization of the project were calculated.

Simulations of the designed unit installed on the roof of the train have shown less additional air reluctance compared to analytical solution of the drag problem. Nevertheless, the MATLAB simulation of the wind power system demonstrated the capability of the system to overcome the excess air drag and supply certain amount of electricity to the load as well. Another important benefit is related to reduction of greenhouse gas emission and fuel economy. The approximation of necessary investment and the payback period has also given positive feedback on feasibility of the proposed renewable energy unit.

Recall that meteorological conditions and geographic characteristics of the route have a significant impact on wind power output. Therefore, since route 
Astana-Almaty connects northern and southern parts of the country, the simulation of other routes, for instance, Astana-Aktau (north-west) where ambient temperature, air density, and altitude undergo through dramatic changes is likely to enhance the feasibility assessment of the proposed model. On the other hand, the flow simulation of the proposed model might be conducted in more advanced software ANSYS Fluent, rather than SolidWorks. As the wagon model taken as the base of all simulations, the proposed unit and its simulation models can be applied to any other wagon type.

Furthermore, the idea of compressed air storage, which will be used during train acceleration, deceleration, and station stops is quite promising and is likely to solve the issue of intermittent power generation.

Calculation of payback period can be improved by clarifying the specifications of all trains currently available and through finalizing the model and price of required components as well as their exact amount. Recall that negotiations with local manufacturers are likely to reduce the cost of the wind power unit. 


\section{References}

[1] US Office of Energy Efficiency \& Renewable Energy. "Electric charging stations are the fastest growing type of alternative fueling station", Internet: www.energy.gov/eere/vehicles/fact-920-april-11-2016-electriccharging-stations-are-fastest-growing-type-alternative, Apr. 11, 2016 [Aug. 20, 2016].

[2] G. Prasanth and T. Sudheshnan,"A renewable energy approach in fast moving trains", Proceedings of the national seminar \& exhibition on non-destructive evaluation NDE 2011, December 8-10, 2011.

[3] Entergy. "A comparison: Land use by energy source - nuclear, wind and solar", Internet: www.entergyarkansas.com/content/news/docs/AR_Nuclear_One_Land_Use.pdf [Aug. $25,2016]$.

[4] M.M. Ehsan, E.G. Ovy, H.A. Chowdhury and S.M. Ferdous. "A proposal of implementation of ducted wind turbine integrated with solar system for reliable power generation in Bangladesh", International Journal of Renewable Energy Research. 2(3), 2012, pp. 397-403.

[5] B. Sindhuja, "A proposal for implementation of wind energy harvesting system in trains", Proceedings of the 2014 International Conference on Control, Instrumentation, Energy and Communication (CIEC), Calcutta, 2014, pp. 696-702.

[6] Y.A. Cengel and J.M. Cimbala. "Flow over bodies: Drag and lift" in Fluid Mechanics Fundamentals and Applications, $3^{\text {rd }}$ ed. New York: McGrawHill Higher Education, 2013.

[7] S. Menaka and A.A. Rao, "Production of electricity using the wind turbine mounted on a moving vehicle", 2011 Annual IEEE India Conference, Hyderabad, 2011, pp. 1-3. 
[8] M. Sofian, et.al. (2014, Sep.). "An evaluation of drag coefficient of wind turbine system installed on moving car", Applied Mechanics and Materials, 660, 2014, pp. 689-693.

[9] J. Sumit, S. D'Silva and M. Ingale. "Utilizing kinetic energy of wind as a source of power in commercial vehicles", International Journal of Renewable and Sustainable Energy, 2(6), 2013, pp. 198-200.

[10] B. Frankovic and I. Vrsalovic. "New high profitable wind turbines", Renewable energy, 24(3-4), 2001, pp. 491-499.

[11] JSC National Company Kazakhstan Temirzholy, Internet: www.railways.kz/en [Sep. 2, 2016].

[12] National and Local Weather Forecast, Hurricane, Radar and Report. Internet: www.weather.com [Aug. 31, 2016].

[13] The Engineering Toolbox. Drag coefficient. Internet: www.engineeringtoolbox.com/drag-coefficient-d_627.html [Sep. 4, 2016].

[14] H. Bengtson. (2010, Jun.). "Drag force for fluid flow past an immersed object", Internet: www.brighthubengineering.com/hydraulics-civilengineering/58434-drag-force-for-fluid-flow-past-an-immersed-object/ [Sep. 10, 2016].

[15] A.Y. Qasim, R. Usubamatov, Z.M. Zain and G.A. Quadir. "The parameters affect on power coefficient vertical axis wind turbine." IIUM Engineering Journal, 13(1), 2012, pp. 59-66.

[16] S.M. Tupe, D.P. Chavan, C.P.Ahvad and A.K. Pathak. "Power generation through wind created by moving train', International Journal of Advance Research and Innovative Ideas in Education, 2(2), 2016, pp. 852-855.

[17] N. Kumar and V.K. Sharma. "Production of electricity by using turbine mounted on train", International Journal of Conceptions on Electrical \& Electronic Engineering, 1(2), 2013, pp. 32-35. 
[18] S. Bharathi. "An approach to electicity generation from vehicles", International Joint Journal Conference on Engineering \& Technology, 4(4), 2010, pp. 39-42.

[19] I. Mahendran. "A Novel Method to Generate Electricity Using Fast Moving Vehicles Train", International Journal for Research in Applied Science \& Engineering Technology, 4(4), 2016, pp. 292-296.

[20] S.Wang and S. Chen. "Blade number effect for a ducted wind turbine", Journal of mechanical sciences and technology, 22, 2008, pp. 19841992.

[21] C.J. Baker. "Train Aerodynamic Forces and Moments from Moving Model Experiments ", Journal of Wind Engineering and Industrial Aerodynamics, 24, 1986, pp. 227-251.

[22] A. C. Mandal and M. Q. Islam. "Aerodynamics and design of wind turbines”, ISBN 984-31-0923-0, published by Bangladesh University of Engineering \& Technology, Dhaka, Bangladesh, September, 2001.

[23] M.J. Werle and W.M. Presz Jr. "Ducted wind/water turbines and propellers revisited", Journal of Propulsion and Power, 24(5), 2008, pp. 1146-1150.

[24] "Kryukov wagon construction factory" Public Joint Stock Company. Passenger wagon of 799 Series, Internet:

www.kvsz.com/index.php?option=com_content\&amp;task=view\&amp;i d=137\&amp;Itemid=309\&amp;lang=ru\&amp;limitstart=10 [Sep. 4, 2016].

[25] US Environmental Protection Agency. GHG Equivalencies Calculator Calculations and References, Internet: www.epa.gov/energy/ghgequivalencies-calculator-calculations-and-references [Sep. 11, 2016].

[26] Delft University of Technology. The Model of the Eco-costs/Value Ratio $(E V R)$, Internet: www.ecocostsvalue.com/EVR/model/theory/2emissions.html [Sep. 3, 2016]. 


\section{Appendices}

\section{$\underline{\text { Appendix A }}$}

\section{AutoCad model}

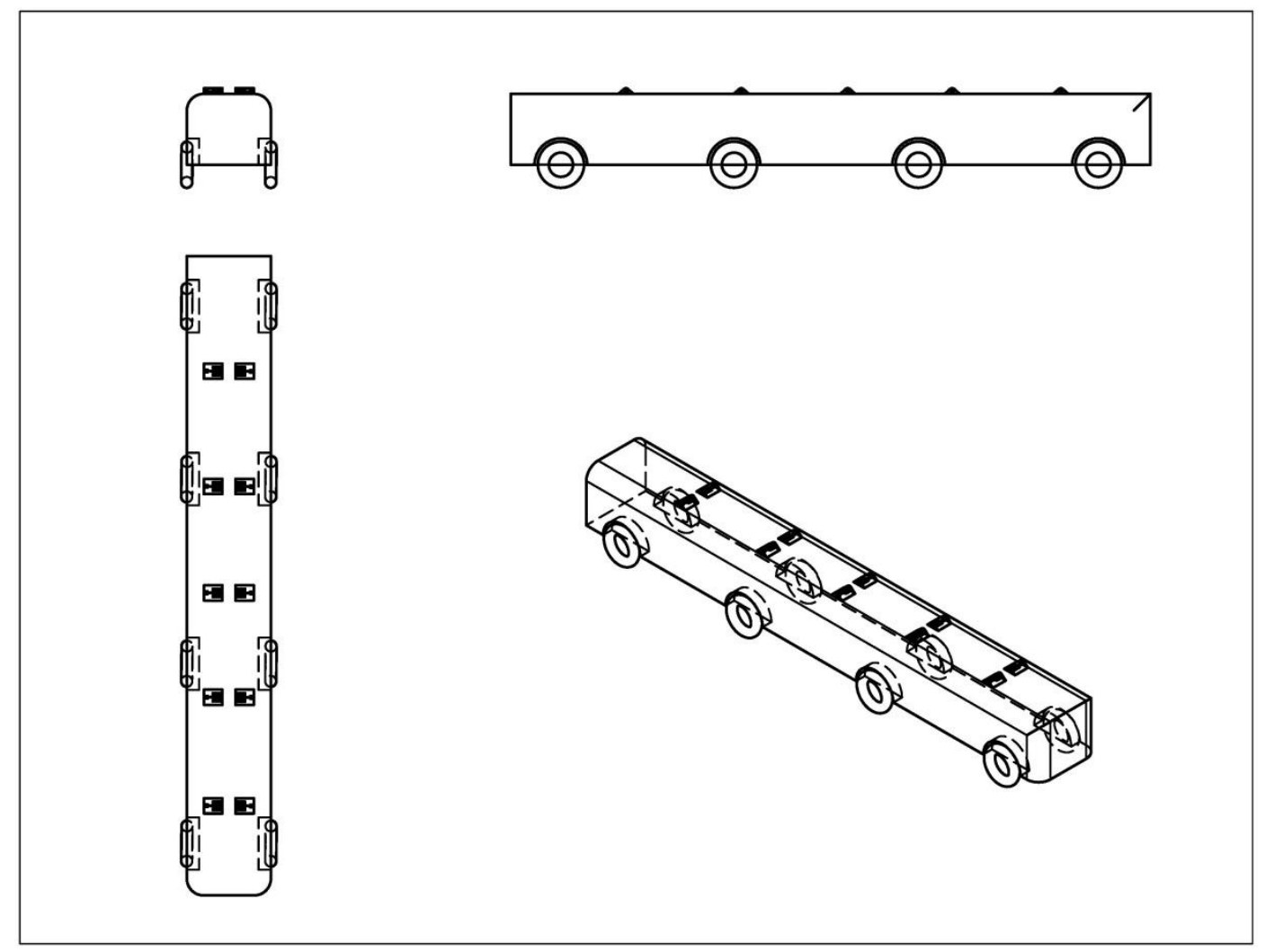

Figure A. 1: Projected view of the wagon with installed units 


\section{$\underline{\text { Appendix B }}$}

\section{SolidWorks simulation results:}

Table B.1 shows key parameters from air flow simulation of wagon without any additional installations. Minimum, average and maximum values of pressure, air speed and drag force are listed. (X) stands for X-axis component of the corresponding parameter. Global and surface parameters were chosen. The number of iterations is 1949 and analysis interval is 94 .

Table B. 1: Air flow simulation results for simple wagon

$\underline{\text { wagon_without_unit }}$

\begin{tabular}{|c|c|c|c|c|c|c|}
\hline Goal name & Unit & Value & Average & Minimum & Maximum & Execution [\%] \\
\hline Global pressure & {$[\mathrm{Pa}]$} & 101642,41 & 101642,4111 & 101642,4091 & 101642,414 & 100 \\
\hline Global speed & {$[\mathrm{m} / \mathrm{s}]$} & 26,651193 & 26,65121031 & 26,65118709 & 26,65123492 & 100 \\
\hline Global speed $(\mathrm{X})$ & {$[\mathrm{m} / \mathrm{s}]$} & $-26,64052$ & $-26,64053242$ & $-26,64055762$ & $-26,64050363$ & 100 \\
\hline Global force & {$[\mathrm{N}]$} & 13831,398 & 13827,69422 & 13806,21875 & 13848,27556 & 100 \\
\hline Global force $(\mathrm{X})$ & {$[\mathrm{N}]$} & $-8441,414$ & $-8458,788639$ & $-8473,125507$ & $-8441,414423$ & 100 \\
\hline Surface pressure & {$[\mathrm{Pa}]$} & 101287,81 & 101287,8573 & 101287,7995 & 101287,9185 & 100 \\
\hline Surface force & {$[\mathrm{N}]$} & 10257,752 & 10250,91837 & 10243,25848 & 10257,75215 & 100 \\
\hline Surface force $(\mathrm{X})$ & {$[\mathrm{N}]$} & $-4306,681$ & $-4307,073345$ & $-4307,631623$ & $-4306,681356$ & 100 \\
\hline
\end{tabular}

Iterations []: 1949

Analysis interval: 94

Value of global force (see Figure B.1) started at nearly 303,923 N from first iteration, and then decreased rapidly down to $14,417 \mathrm{~N}$ at iteration №32. Afterwards it reached the steady state at $13,830 \mathrm{~N}$ starting from $300^{\text {th }}$ iteration. 


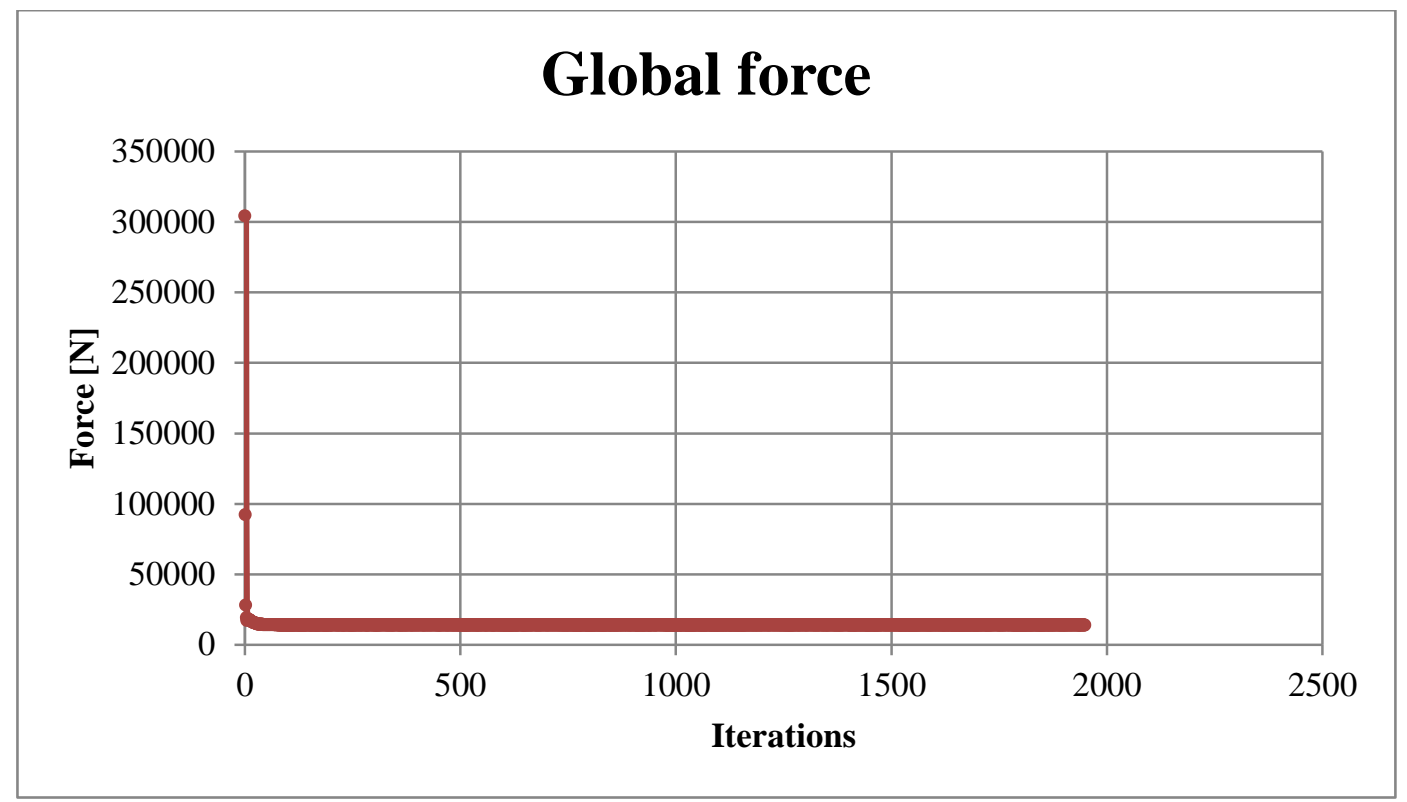

Figure B. 1: Graph of global force

Value of total pressure (see Figure B.2) started at about 102,492 Pa from first iteration, and then decreased rapidly down to 101,281 $\mathrm{Pa}$ in 4 iterations. Then it slightly increased reaching 101,287 $\mathrm{Pa}$ at iteration №26. Afterwards it reached the steady state at 101,288 Pa starting from iteration №100.

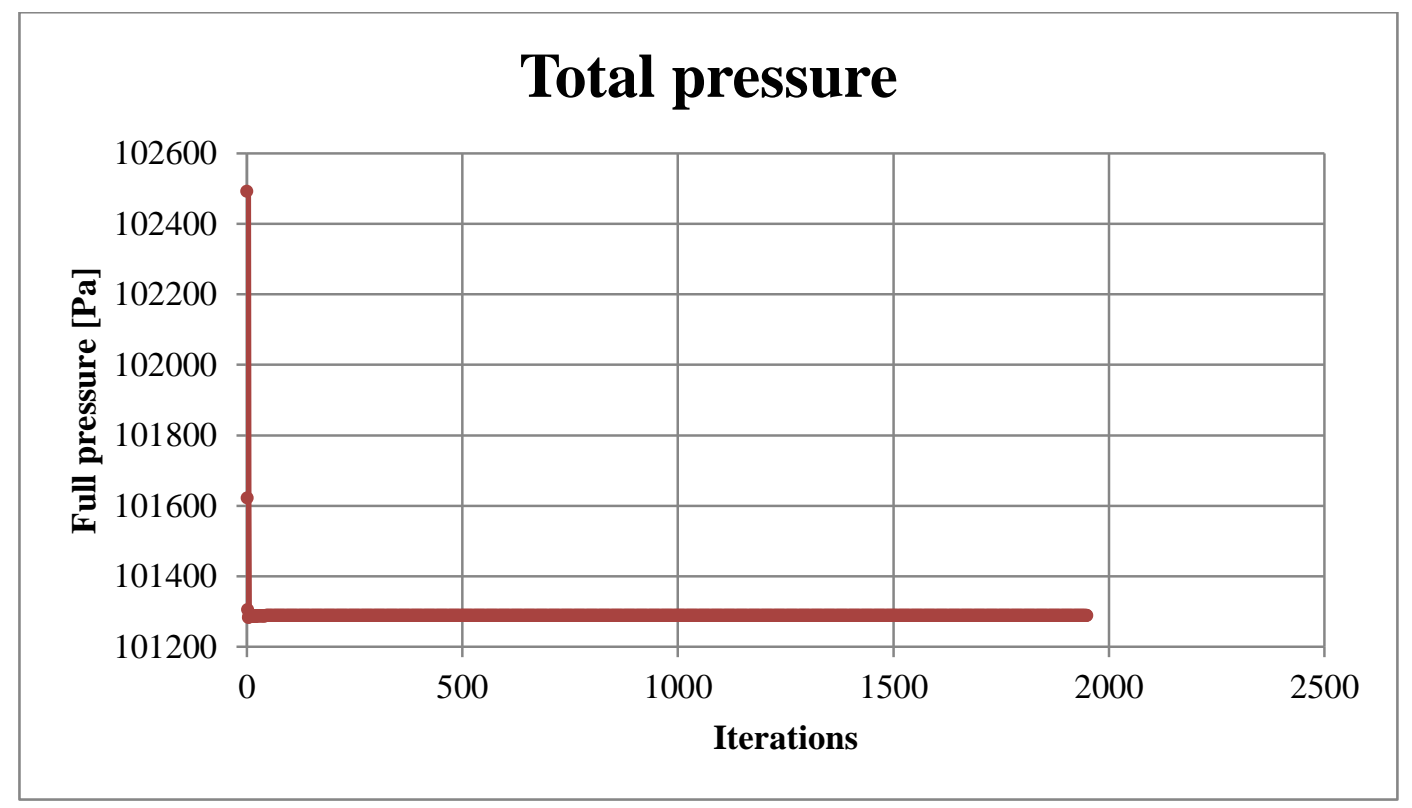

Figure B. 2: Graph of total pressure 
The wind speed (see Figure B.3) started at nearly $27 \mathrm{~m} / \mathrm{s}$ from first iteration, and then decreased slightly down to $26.7 \mathrm{~m} / \mathrm{s}$ at iteration №193. Afterwards it reached the steady state at $26.65 \mathrm{~m} / \mathrm{s}$ starting from $211^{\text {th }}$ iteration.

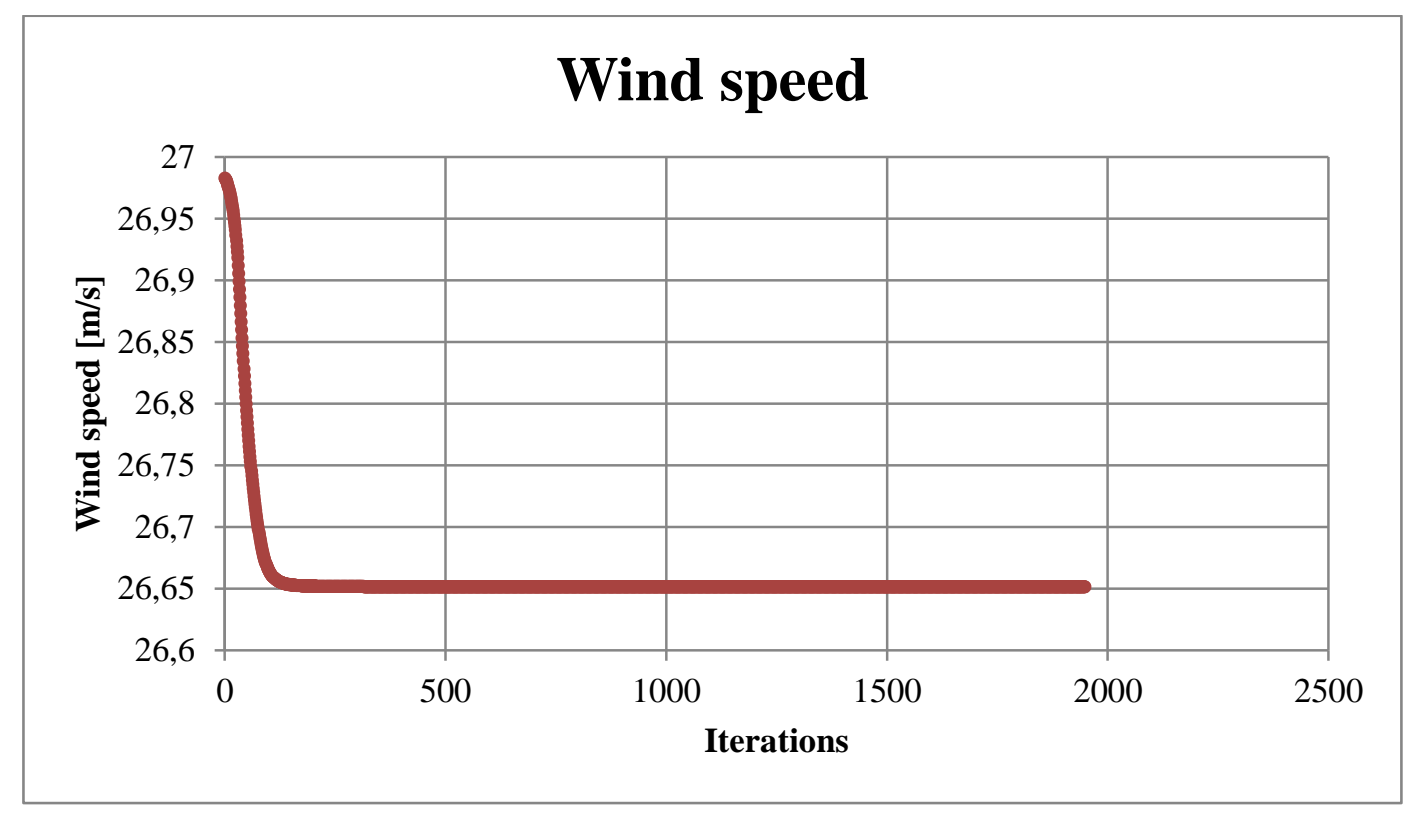

Figure B. 3: Graph of wind speed

Table B.2 shows key parameters from air flow simulation of wagon with ten wind power generation units installed. Minimum, average and maximum values of pressure, air speed and drag force are listed. (X) stands for X-axis component of the corresponding parameter. Global and surface parameters were chosen. The number of iterations is 1868 and analysis interval is 93 . 
Table B. 2: Air flow simulation results for wagon with ten turbines

wagon_with_unit

\begin{tabular}{|c|c|c|c|c|c|c|}
\hline Goal name & Unit & Value & Average & Minimum & Maximum & Execution [\%] \\
\hline Global pressure & {$[\mathrm{Pa}]$} & 101642,56 & 101642,5487 & 101642,542 & 101642,5582 & 100 \\
\hline Global speed & {$[\mathrm{m} / \mathrm{s}]$} & 26,656174 & 26,65621456 & 26,65607994 & 26,65633965 & 100 \\
\hline Global speed $(\mathrm{X})$ & {$[\mathrm{m} / \mathrm{s}]$} & $-26,64627$ & $-26,64631004$ & $-26,64643493$ & $-26,64618723$ & 100 \\
\hline Global force & {$[\mathrm{N}]$} & 14080,936 & 14033,85552 & 13964,74726 & 14116,01929 & 100 \\
\hline Global force $(\mathrm{X})$ & {$[\mathrm{N}]$} & $-8069,699$ & $-8078,576368$ & $-8090,80693$ & $-8059,148299$ & 100 \\
\hline Surface pressure & {$[\mathrm{Pa}]$} & 101278,98 & 101279,123 & 101278,9759 & 101279,2595 & 100 \\
\hline Surface force & {$[\mathrm{N}]$} & 10563,377 & 10546,10242 & 10530,72341 & 10564,62031 & 100 \\
\hline Surface force $(\mathrm{X})$ & {$[\mathrm{N}]$} & $-4064,247$ & $-4062,452413$ & $-4064,332001$ & $-4060,530359$ & 100 \\
\hline
\end{tabular}

\section{Iterations []: 1868}

Analysis interval: 93

The global force (see Figure B.4) started at nearly 308,653 N from first iteration, and then decreased dramatically down to 18,366 at iteration №6. Then it slightly decreased reaching 13,990 $\mathrm{N}$ at iteration №96. Afterwards it reached the steady state at $14,080 \mathrm{~N}$ starting from $144^{\text {th }}$ iteration.

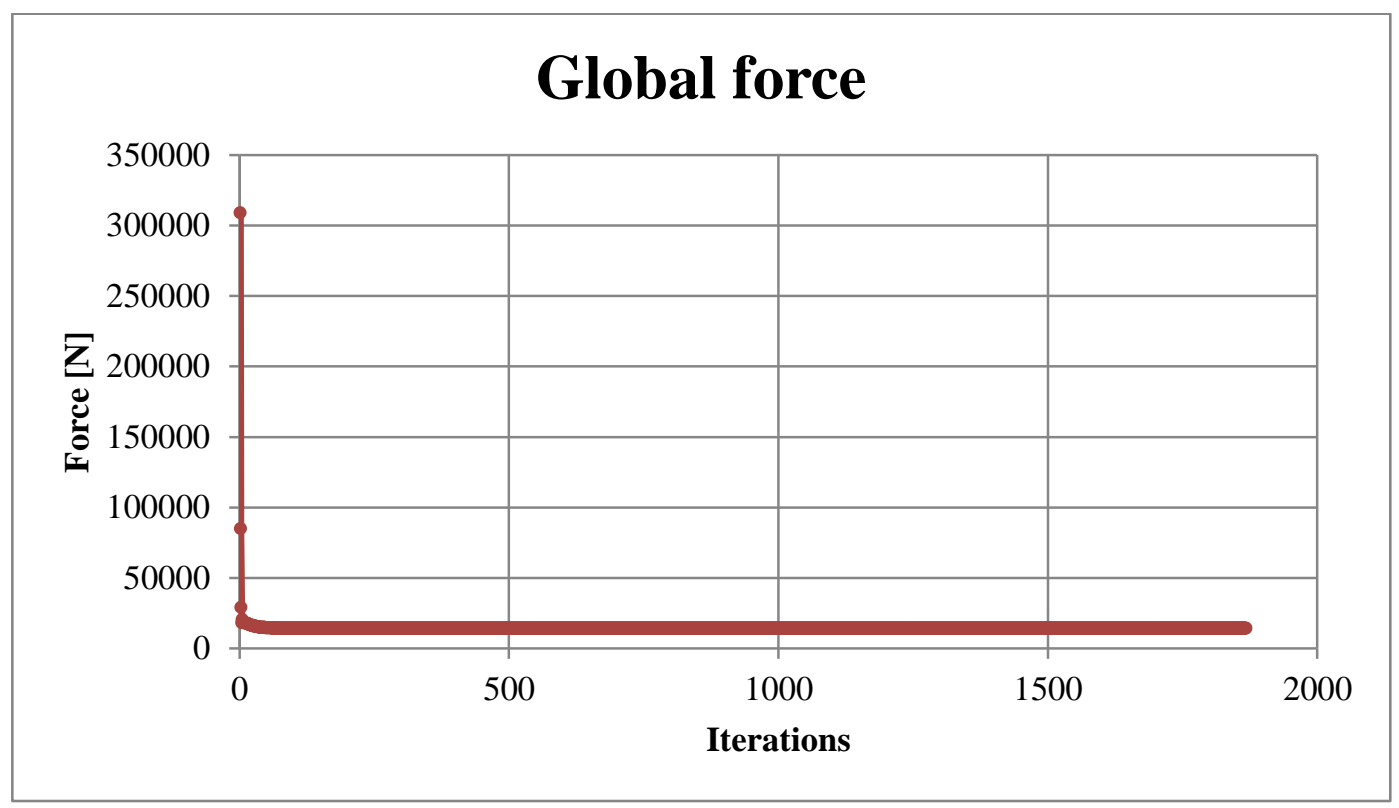

Figure B. 4: Graph of global force 
The total pressure (see Figure B.5) started at approximately 102,492 Pa from first iteration, and then decreased down to 101,281 Pa at iteration №4. Afterwards it reached the steady state at $101,288 \mathrm{~Pa}$ starting from $59^{\text {th }}$ iteration.

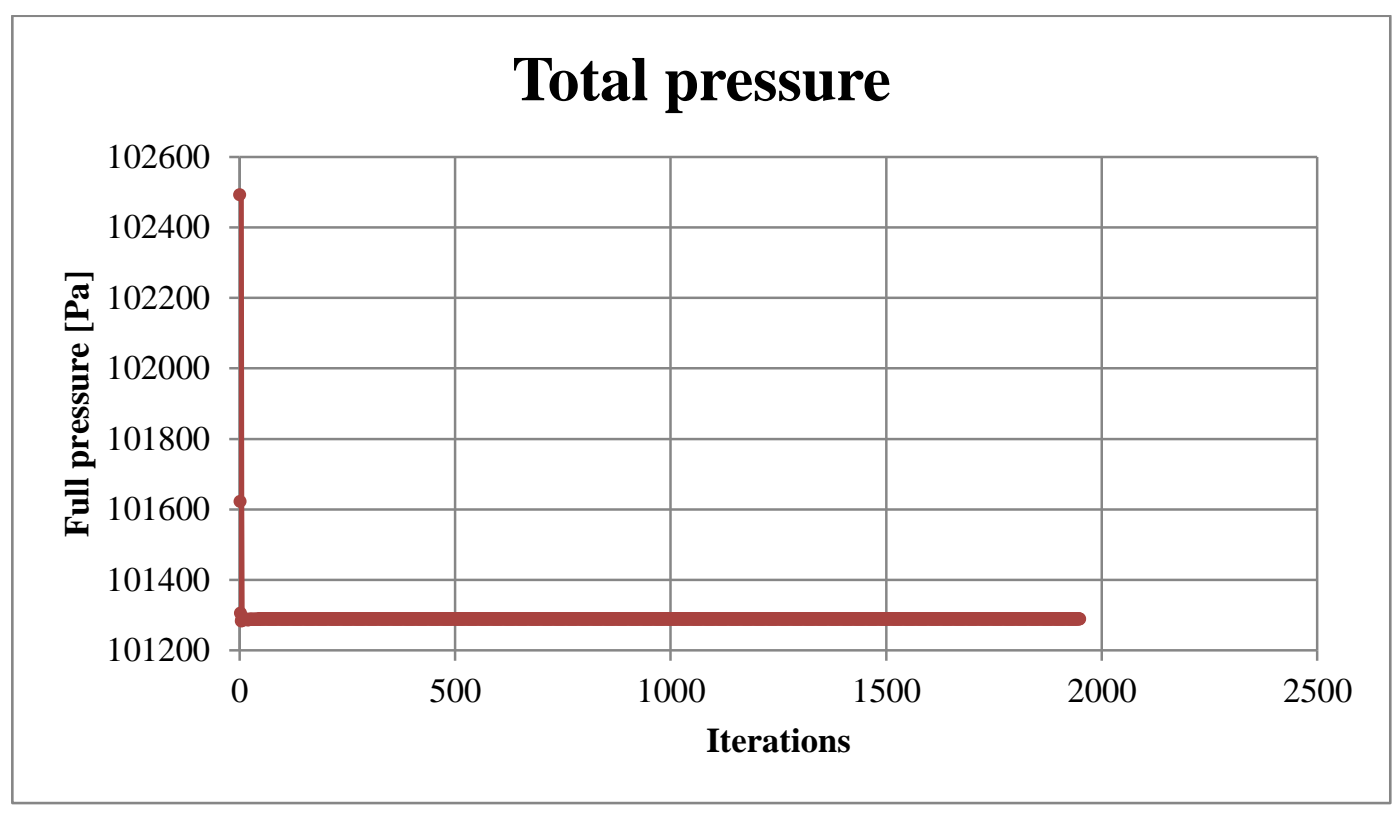

Figure B. 5: Graph of total pressure

The wind speed (see Figure B.6) started at nearly $27 \mathrm{~m} / \mathrm{s}$ from first iteration, and then decreased down to $26.7 \mathrm{~m} / \mathrm{s}$ at iteration №131. Then it reached steady state at $26.65 \mathrm{~m} / \mathrm{s}$ starting from iteration №188. However, slight fluctuations occur beginning from $1336^{\text {th }}$ iteration. 


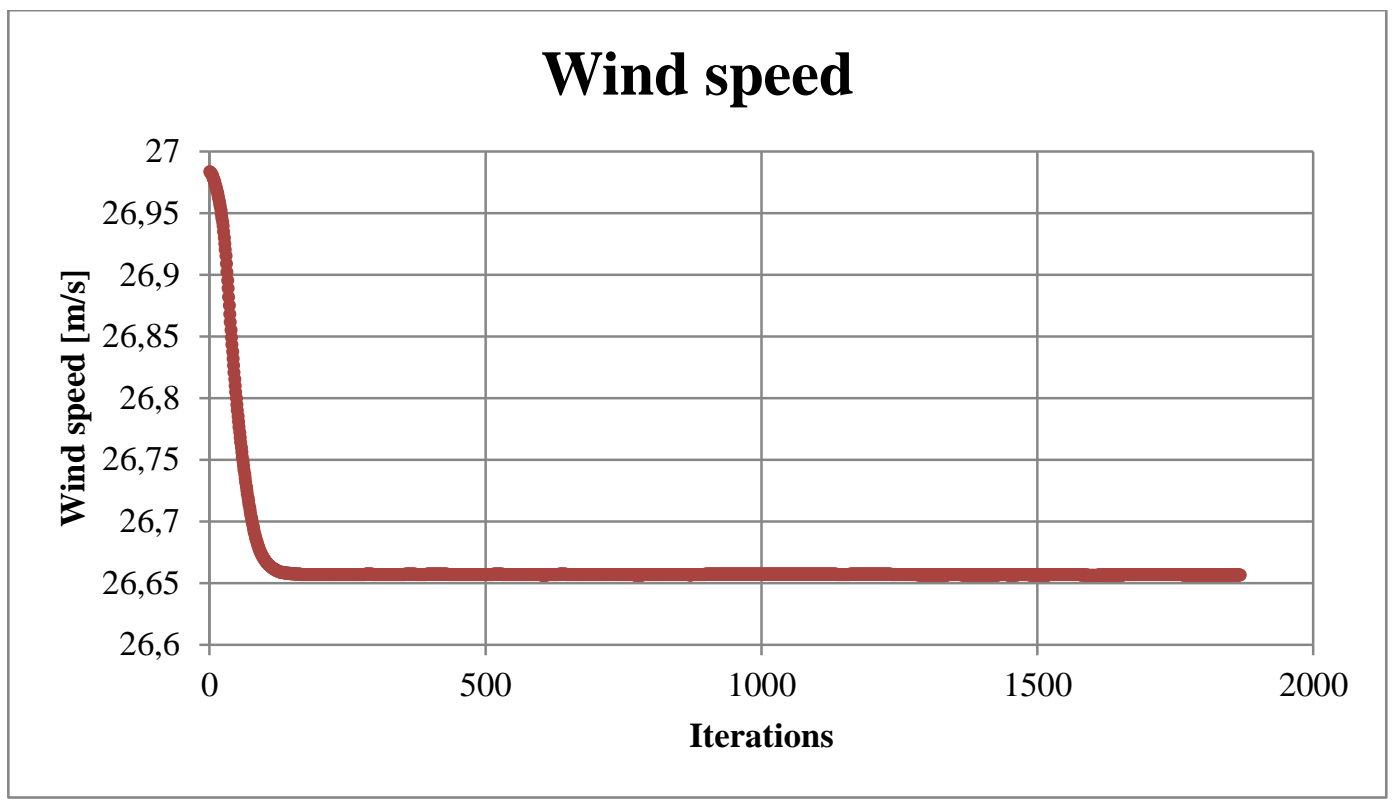

Figure B. 6: Graph of wind speed

Air flow trajectories over simple wagon are shown in Figure B.7. It is observed that the intensity of moving air streams on surface of the wagon is not high. The wind speed varies between $2.838 \mathrm{~m} / \mathrm{s}$ and $22.676 \mathrm{~m} / \mathrm{s}$.

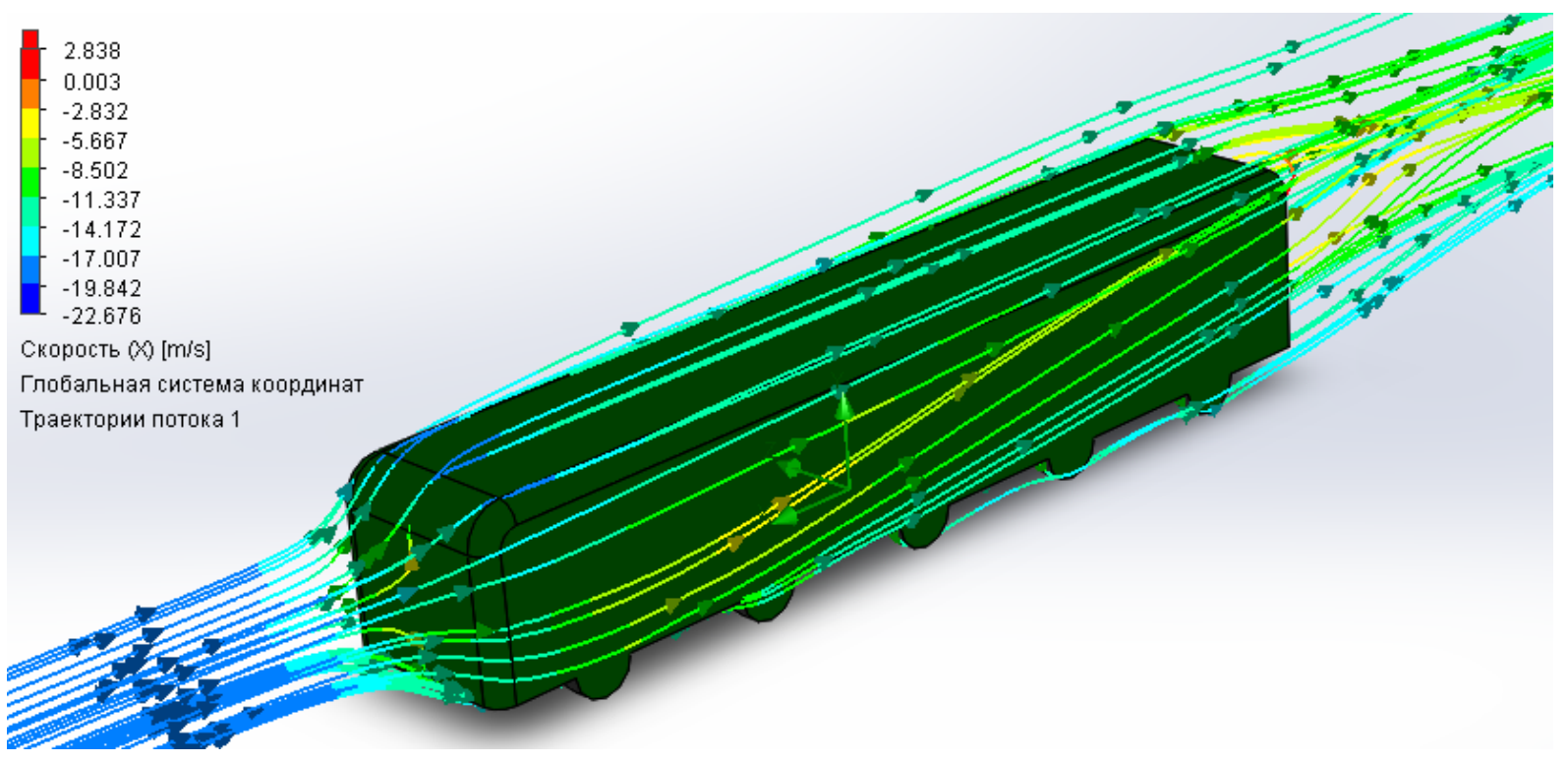

Figure B. 7: Air flow simulation of single wagon

Air flow trajectories over wagon and five wind power generation units installed on only one side of the roof are shown in Figure B.8. It is observed that the intensity of moving air streams on surface of the wagon is higher where units are installed. Moreover, the overall wind speed is increased; it varies between 
$4.587 \mathrm{~m} / \mathrm{s}$ and $30.937 \mathrm{~m} / \mathrm{s}$, which can be observed from the bar at the left side of the picture.

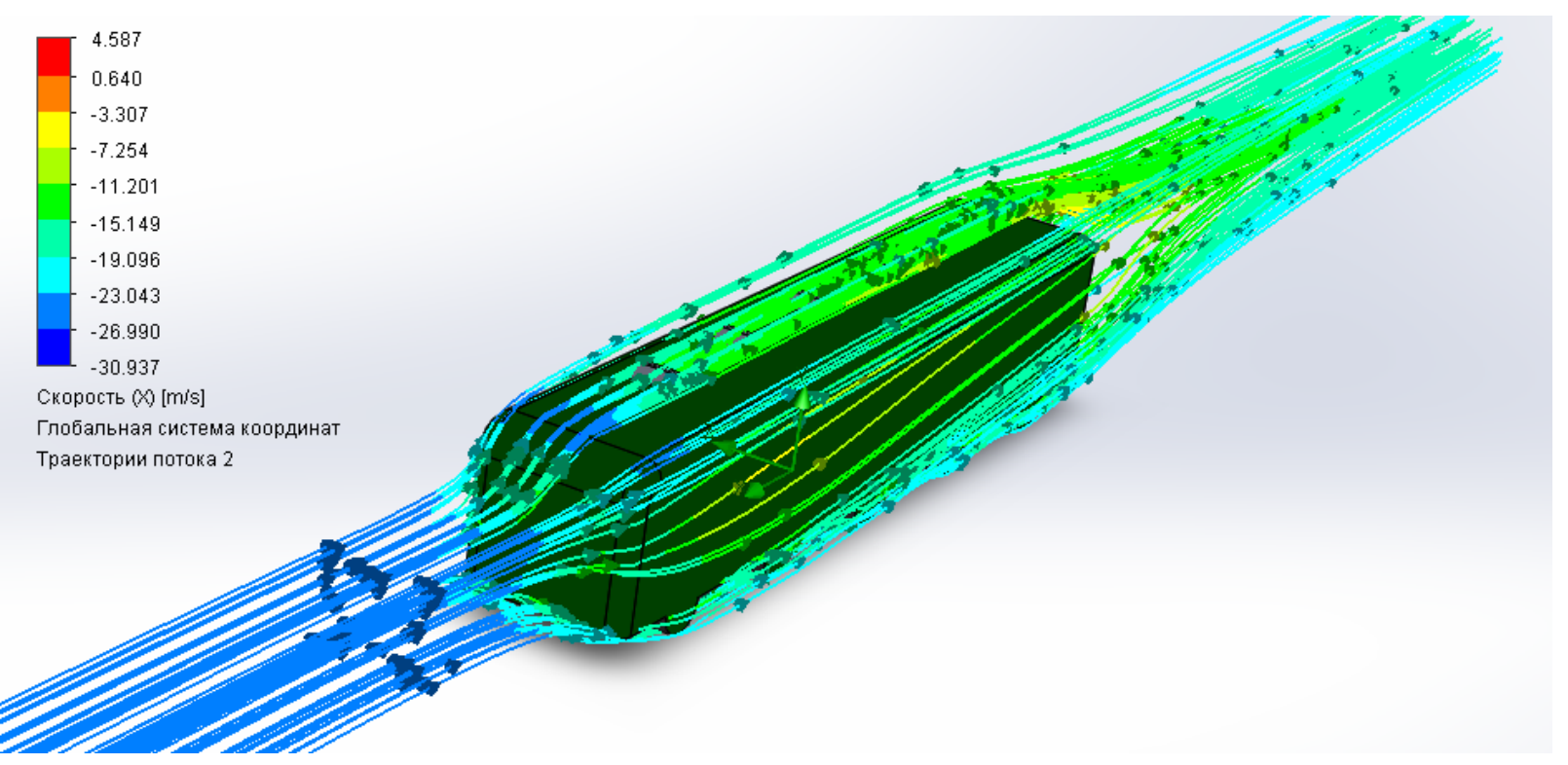

Figure B. 8: Air flow simulation of wagon with five units installed

Air flow trajectories over wagon and ten wind power generation units installed on the roof are shown in Figure B.8. It is observed that the intensity of moving air streams on surface of the wagon is even higher than the previous case. The overall wind speed decreased due to air drag, and varies between 2.838 $\mathrm{m} / \mathrm{s}$ and $22.676 \mathrm{~m} / \mathrm{s}$. The air flow intensity is expectedly higher at the roof of the wagon.

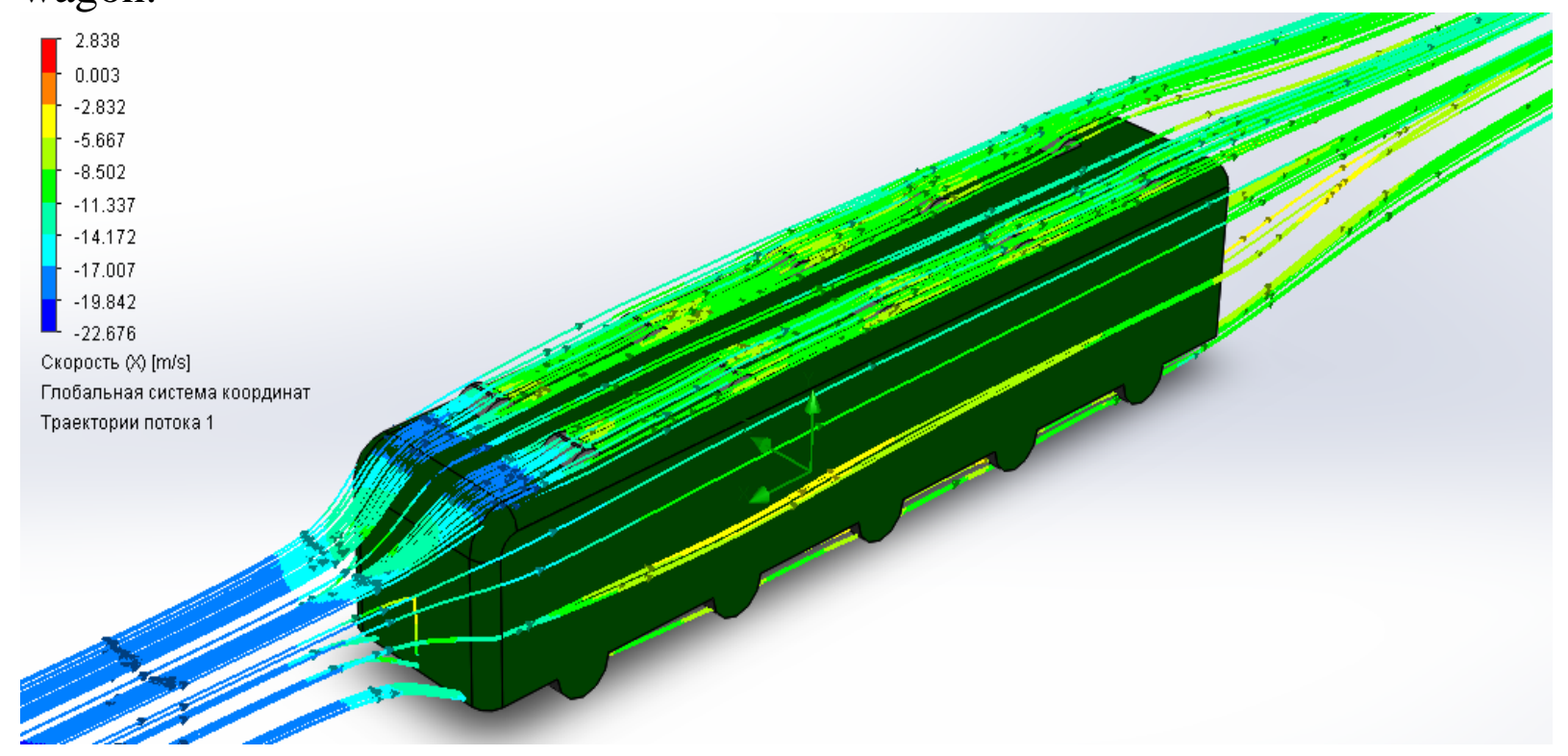

Figure B. 9: Air flow simulation of wagon with ten units installed 


\section{$\underline{\text { Appendix C }}$}

\section{MATLAB code for generation of .mat file:}

close all, clear all, clc

$\operatorname{disp}($ 'short');

A = dlmread('densityshort.csv',';',[0 045600 1]);

B = dlmread('speedshort.csv',';', [0 045600 1]);

time $=\mathrm{A}(:, 1)$

density $=\mathrm{A}(:, 2)$;

speed $=\mathrm{B}(:, 2)$;

save('speed_short.mat','time','speed');

save('density_short.mat','time','density');

disp('long');

A = dlmread('densitylong.csv',';',; [0 067740 1]);

B = dlmread('speedlong.csv',';',; [0 067740 1]);

time $=\mathrm{A}(:, 1)$;

density $=\mathrm{A}(:, 2)$;

speed $=\mathrm{B}(:, 2)$;

save('speed_long.mat','time','speed');

save('density_long.mat','time','density'); 
MATLAB Simulink integrated wind turbine block is used to estimate values of power coefficient $C p$ and tip ratio Lambda. The inner structure of the wind turbine block is provided in Figure $\mathrm{C} 2$. Power coefficient of the turbine is calculated to be equal to 0.487 .

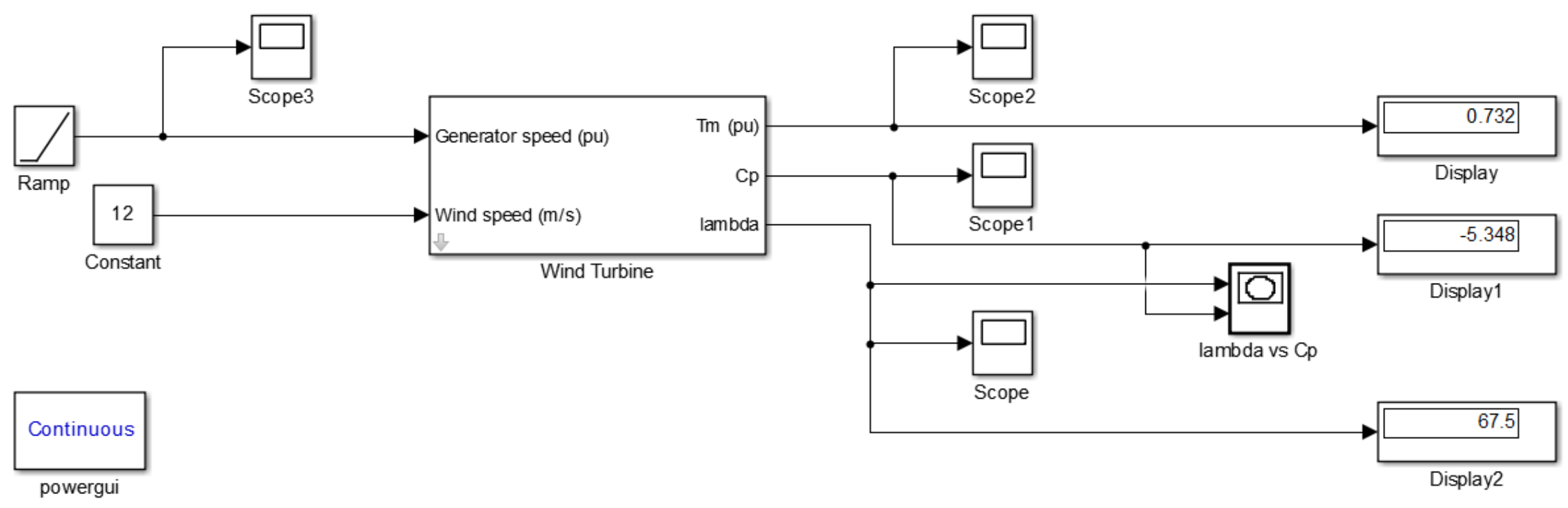

Figure C. 1: Wind power system block 


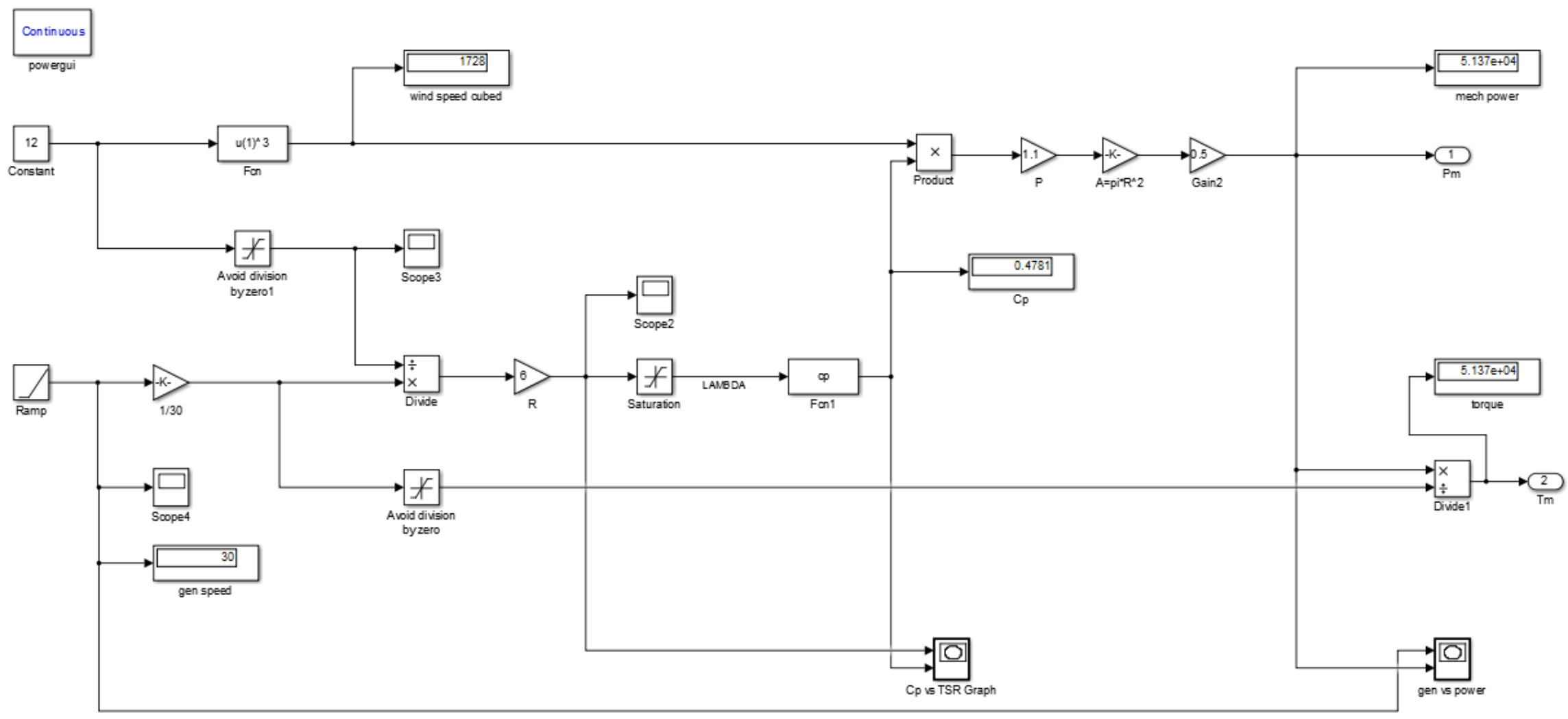

Figure C. 2: Estimation of the power coefficient 